\title{
La arqueología del Inka en Chile
}

\author{
Mauricio Uribe Rodríguez
}

\section{INTRODUCCION}

Debido a que en estos momentos nos encontramos estudiando en forma sistemática la problemática incaica en un sector del Norte Grande del pais, Caspana (región del Loa Superior), hemos decidido abocarnos a la tarea de comprender el desarrollo de la investigación arqueológica de este tema en Chile, discriminando los aspectos positivos y negativos, a nuestro parecer, susceptibles de ser imitados, mejorados o superados.

Es muy sabido, gracias a la historia misma, que los incas anexaron a su imperio, el Tawantinsuyu, casi la mitad de nuestro actual territorio continental y es cada vez más claro que esto fue así, porque sus restos materiales se distribuyen de manera bastante continua desde Arica en el extremo norte, hasta el Cachapoal en la zona centro-sur. Sin embargo, a pesar de que las noticias y el registro arqueológico han ido aumentando con el tiempo, creemos que, excepto por unos pocos colegas, son escasas las investigaciones temáticas que abordan este problema en forma sistemática como línea de trabajo. En general, los arqueólogos nos referimos al tema de manera tangencial, ya que lo mencionamos en la medida que se nos atraviesa en el camino de otros problemas que estamos estudiando, lo cual se traduce en la ausencia de trabajos de síntesis para el periodo. De este modo, tenemos una gran historia de la investigación sobre, por ejemplo, el Arcaico, el Formativo, Tiwanaku; las culturas el Molle y Diaguita, los desarrollos agroalfareros tempranos de Chile Central, la cultura Aconcagua, etc. Lo anterior es contradictorio si consideramos que los restos materiales del paso del Inka son los más abundantes y variados que los de cualquier otro período de la prehistoria chilena, y porque además en esos momentos se produce la máxima integración a los Andes Centrales y, por lo tanto, con el mundo andino. Conjuntamente, para dicho período y esta parte del territorio sudamericano se cuenta con el apoyo documental de la Etnohistoria e incluso de la Etnografía, el cual no se tiene para épocas más tempranas, incrementando sobremanera el potencial de los datos "duros". Por último, es un problema que tiene implicancias que rebasan los límites nacionales, puesto que los datos resultan ser de interés internacional como lo han demostrado congresos, simposios, jornadas y encuentros entre colegas en torno al tema (p.e., STEHBERG, 1991).

\footnotetext{
'Resultado del Proyecto FONDECYT 1970528, "El dominio lnka en las quebradas altas del Loa Situerior : un acercamiento al pensamiento político andino".
} 
En este sentido, nos acogemos al Ilamado que hace V. Castro (1992), a partir de una prospección por las tierras altas del Desierto de Atacama, donde luego de una dinámica como la descrita, surge la siguiente reflexión:

"Las noticias que hemos entregado en este recuento nos permiten evaluar cuán poco sabemos aún de la ocupación inkaica en la región y cuánto trabajo básico es necesario desarrollar para contar con los datos que permitan comprender esta fase de la prehistoria regional y las distintas modalidades y estrategias de ocupación del espacio por parte de los Inkas" (Op. cit., p. 152).

Por lo tanto, en esta ocasión, es nuestra intención contribuir con una reflexión propia sobre los por qué de esta situación, introduciéndonos -aunque sin ser todo lo exhaustivo que nos gustaría- en los problemas específicos tratados, los materiales analizados, los modos de análisis, los enfoques interpretativos y los resultados obtenidos de los trabajos realizados y publicados, especialmente, por los arqueólogos y no-arqueólogos (historiadores y otros) que se han enfrentado a la presencia inca en Chile a través de su materialidad. Para ello, separamos los artículos por zonas (Norte Grande, Norte Chico, Chile Central y Sur), los temas tratados (poblados, instalaciones, cementerios, agricultura, minería, camino), materiales (cerámica, arquitectura, textiles, metales, momias) e interpretaciones que se derivan de ellos.

Ahora bien, lo primero que resalta en esta revisión de la Arqueología del Inka en Chile, es que casi del centenar de publicaciones que hemos pesquizado hasta ahora, existe un sólo libro monográfico (STEHBERG, 1995), mientras que el resto corresponde en su mayoría a artículos de revistas o pequeños capítulos de libros de prehistoria local, regional o nacional (p.e., Santoro y Ulloa, 1985 ; Bittman et al., 1978 ; Mostny, 1971).

\section{Eventos de la arqueologia del InKa en Chile}

\section{El Norte Grande}

Arica y sus alrededores. Esta corresponde a la zona del Norte Grande comprendida por los Valles Occidentales ubicados entre el desierto costero del extremo sur del Perú por el norte y la quebrada de Camarones, en Chile, por el sur, cuyos cursos de agua alcanzan a desembocar en el Océano Pacífico. Aquí se reconocen tres importantes oasis : Lluta, Azapa y Camarones, cuyos restos culturales dan cuenta de una dinámica cultural muy intensa y extensa en el tiempo como en el espacio, ya que además del litoral, involucran las tierras altas de la Sierra, entre el cordón montañoso de Huaylillas y la cordillera occidental de los Andes, y parte del Altiplano.

Para el período que nos preocupa, podemos citar los sitios de Mollepampa al interior de Lluta (SANTORO Y UlloA, 1985), Alto Ramírez ó Az-1 5 en Azapa mismo (SANTORO y MUÑoz, 1981) y Hacienda Camarones de la quebrada homónima (NIEMEYER, 1963), lo cuales son bastante conocidos de acuerdo a la literatura especializada. Sin embargo, también existe un gran número de otros sitios que más bien se han registrado en la Sierra, especialmente, de Arica y Camarones. detectados gracias a prospecciones sistemáticas de los cursos altos de las quebradas. De este modo, de norte a sur, destacan el sector de Zapahuira-Socoroma en Lluta, donde se han observado, entre otros, poblados afectados

\footnotetext{
'En general, los trabajos revisados coinciden en denominar de este modo a las instalaciones arquitectónicas incas acotadas a una serie de recintos, de característico trazado rectangular, asociados a patios amurallados y casi siempre vinculados al cannino imperial o ramales de éste (Vid., p.e., RNil:INe, 1981)
} 
por ocupación incaica, terrazas agrícolas o andenerías asociadas, "tambos" ' y tramos del camino imperial. Este panorama se tiende a repetir en los sectores de Belén-Tignamar en las cabeceras de Azapa, se les une Codpa en la quebrada de Vitor y Miñita un poco más al sur, además del mencionado Camarones. No obstante, en este último notamos la expresión más continua de vestigios de la época, ya que aparecen desde la desembocadura, representados por un poblado en su parte norte y cementerios en la sur; hasta la Sierra con Chilcaya en el Salar de Surire en la frontera con Bolivia (NIEMEYer y SCHIAPPACASSE, 1988).

Es interesante notar que, de acuerdo a las zonas que hemos distinguido, tenemos dos clases de evidencias mencionadas por los arqueólogos. En primer lugar, gracias a sus cualidades climáticas adecuadas para la conservación de material perecible, en la costa existe una abundante recuperación de textiles y otros objetos igualmente delicados como los cordeles contables o "kipus" y gorros tipo "fez" ", a parte de la alfarería e incluso la metalurgia (ÁlVAREZ, 1992-93), y también el registro de arquitectura no sólo en piedra (p.e., plataforma o "ushnu" en Az-15 [SilvA, 1994]), sino también hecha con materias primas vegetales, por ejemplo, madera y "totora" (PIAZZA, 1981). Por otro lado, la proliferación de cementerios en los tramos medio y bajo de tales quebradas, sobretodo en Azapa como lo demuestra Az-15 en Pampa Alto Ramírez y algunos inéditos de Playa Miller en la costa sur de Arica ( $\mathrm{FoCACCI}, 1981$ ), han entregado una buen cantidad de piezas completas. En cambio, en la Sierra los niateriales muebles se restringen sobretodo a fragmentos de cerámica y ecofactos, pero abundan datos sobre arquitectura de poblados y tambos (Chacón y Orellana, 1982 ; Muñoz, 1986 ; Muñoz y Chacama, 1991; Muñoz et al., 1987 ; Niemeyer, 1962 ; Niemeyer y SchiapPaCASSE, Op. cit. ; Santoro et al., 1987), la agrohidráulica representada por las andenerías (MUÑOZ, 1986 ; MuÑoz et al., 1987), silos para almacenaje, así como tramos del camino con características sencillas y también muy elaboradas entre las que destacan los empedrados, escalones, desagües y muros, correspondientes a las prácticas más clásicas del imperio (SANTORO, 1983).

Por tanto, fácilmente, se aprecia que existe una considerable cantidad, variedad y calidad de datos que configuran el registro de la presencia incaica en los Valles Occidentales del extremo norte del país, de hecho parte de su alfarería sirvió para construir uno de los tipos cerámicos, Saxamar (DaUELSBERG, 1959-61 ; MunizAGA, 1957), el cual ha servido de indicador diagnóstico de dicha presencia no sólo en Chile, sino también en Bolivia y Argentina. Sin embargo, prácticamente todas las interpretaciones sobre el proceso y los distintos aspectos de la expansión del Tawantinsuyu derivado de los mismos sitios, materiales y contextos presentados, en la práctica se reducen a explicarla a través de "colonias" altiplánicas al servicio del Cuzco :

"La incorporación de esta zona al imperio inkaico ocurrió indirectamente a través de los señorios o reinos altiplánicos como los lupacas y carangas que habían logrado cierto nivel de control sobre los señoríos de Arica" (S^NTORO Y UL.LOA, $1985: 61$ ).

En términos de cultura material, principalmente, esto se debe a que en los sitios habitacionales de las tierras altas las investigaciones han concluido que los fragmentos cerámicos reconocidos como propios de la poblaciones costeras o "vallunas", por ejemplo, tipos Pocoma y Gentilar (DauelsBerg, Op. cit. y 1972-73 ; URIBE, 1997), aparecen en una proporción menor a los del altiplano, por ejemplo, tipos Saxamar o Inca-Pacajes (MUNIZAGA, Op. cit.). Esto significa que grupos altiplánicos representados por el tipo Chilpe (DAUELSBERG,

\footnotetext{
${ }^{3}$ Su nombie deriva de la similitud fonnal con el bonete del Cercano Oriente, el cual por analogia con los dibujos del conocido cronista mestizo F. Guaman Poma de Ayala, se considera un signo identificatorio de las poblaciones altiplánicas del Collasuyo.
} 
$O p$. cit.), con anterioridad habrian ocupado las cabeceras de las quebradas, interviniendo los asentamientos de las poblaciones vallunas de la Sierra, lo cual sería el trampolín para la posterior expansión inca que habría conquistado los núcleos de origen de aquellos en el Altiplano Circumtitikaka y, en consecuencia a los grupos de la Sierra de Arica. Por su parte, la interpretación histórica existente respecto al problema, elaborada en forma bastante conservadora, tiende a apoyar este modelo sin mayor crítica, pues sus fundamentos corresponden a los datos existentes para los Andes Centrales y se ha ahondado poco en la etnohistoria local (Cfr. SANTORO et al., 1987 ; SiLva, 1992-93).

Por consiguiente, se establece una analogía directa, casi étnica, entre alfarería y grupos culturales, al mismo tiempo que, las diferencias porcentuales son entendidas en forma muy mecánica como "dominio político". Lo anterior además, no considera que, por su parte, en Azapa y su litoral se encuentra una Cultura Arica muy fuerte cuya cultura material, en la práctica, es impermeable a la influencia altiplánica como inca, a diferencia de Lluta y Camarones (URIBE, 1997), ya que las evidencias cerámicas aquí, sobretodo de lós grupos altiplánicos, no tiene la incidencia como para pensar que estaban previamente instalados en Azapa durante el período intermedio tardío y, menos aún, que habrian dominado a la Cultura Arica.

La Pampa del Tamarugal y la costa arreica. Esta zona se distingue de la anterior, por una ausencia de cursos de agua que desemboquen en el mar, lo cual se hace extensivo hasta el río Loa, por lo tanto, de acuerdo a los restos arqueológicos las ocupaciones humanas se han concentrado en la costa, en las quebradas de la Pampa del Tamarugal como Tarapacá, Pica y Guatacondo, y en el Altiplano. A pesar de que en este vasto territorio los estudios son mucho más esporádicos, se nota la existencia de una entidad cultural distintiva conocida como Pica-Tarapacá (Moragas, 1995) que, fácilmente, se puede discriminar de las de Valles Occidentales y de aquellas del Desierto de Atacama, la cual estaría en contacto con el Tawantinsuyu.

No obstante, creemos que por la misma escasez de trabajo arqueológico en la zona el registro de la presencia inca aún se considera "leve" (Moragas, Op. cit. : p. 75), aún cuando existen evidencias que tienden a contradecir este panorama. De hecho, cerca de Iquique destaca el "santuario de altura" de Cerro Esmeralda, una práctica exclusiva del imperio en el territorio del Collasuyu (RAFFINO, 1981), pero que en este caso tiene la particularidad de ubicarse no en la cordillera de los Andes, sino que en la de la Costa. Por lo tanto, se trata del santuario más bajo y occidental de dicha porción del Tawantinsuyu $(905 \mathrm{~m})$, pero que cumple con casi todas las características reconocidas en estos casos, excepto por la ausencia de estructuras arquitectónicas, lo cual también puede deberse a la explosión que accidentalmente reveló su existencia. Con todo, tenemos un entierro de dos cuerpos juveniles, asociados a prendas textiles, alfarería, metales y otra serie de objetos orgánicos, todos a primera vista de origen foráneo y de estilo absolutamente "cuzqueño", entre los cuales destacan las conchas de "spondylus". El contexto se encuentra vinculado al cerro Huantajaya que le enfrenta, donde se explotaba una mina de plata (CHECUR^, 1977). Esta misma situación, probablemente, estaría reflejada en algunas cumbres altiplánicas del interior ubicadas sobre los 5000 msnm (SANHUEZA, 1986).

Por otra parte, en la costa también se tienen noticias de cementerios como Bajo Molle y Patillos al sur de Iquique, los cuales se repiten en los oasis de la Pampa del Tamarugal con los sitios Pica-2 y, especialmente, Pica-7 en el valle homónimo (NúÑez, L., 1965 a y 
b), e incluso en las tierras altas de éste como ocurre con Collacagua que además se asocia a un tambo (Niemeyer, 1962). En este sentido, como en otras épocas, Pica se convierte en un espacio privilegiado para detectar la presencia lnca, del mismo modo que la quebrada de Tarapacá. A lo largo de ella, pero sobretodo en los ałrededores de Cariquima, aparecen tambos y los santuarios de altura arriba mencionados (Moragas, 1995 ; Sanhueza, Op. cit.), mientras que más abajo se registran cementerios, importantes obras de canalización, tramos del camino imperial y aldeas como el mismo Tarapacá Viejo (NúÑEZ, P., 1984). Siguiendo hacia el sur, nos encontramos con algunas evidencias en Guatacondo, principalmente funerarias, y otras de la misma clase en la costa de la desembocadura del río Loa donde se encuentra Caleta Huelén-23 (NùNEZ, L., 1971).

Por lo tanto, observamos que existe un panorama muy semejante al de los Valles Occidentales, en cuanto se reconocen la misma variedad de sitios, es decir, poblados, tambos, complejos agrohidráulicos, caminos, minas y, en especial, cementerios, todos los cuales se ubican a lo largo de gran parte de la gradiente altitudinal. Asimismo, los materiales son igualmente variados y abundantes, distinguiéndose la presencia de alfarería, textiles y metales, algunos tan "incaicos" como los de Cerro Esmeralda. Sin embargo, volvemos al problema de la investigación en la zona, ya que la mayoría de los datos, corresponde a menciones escuetas y generales, notándose una importante ausencia de monografias sobre el tema y sus derivados.

De hecho, esto implica que la interpretación no varie mucho de la dada para los Valles Occidentales, por lo cual tampoco existe una reflexión más profunda de la situación local :

"Las influencias sobre el complejo Pica son consecuencia de la expansión del Imperio a través de los centros altiplánicos, con utilización de vías de desplazamiento establecidas en períodos anteriores" (MORAGAS, 1995 : p. 76).

En este sentido, otra vez tenemos que la respuesta arqueológica se basa en la presencia de cerámicas como la Saxamar y gorros tipo fez, objetos que serían la expresión de las poblaciones altiplánicas que dominan la región en favor del Inka. En suma, son obviados datos demasiado importantes a la hora de establecer una explicación como ocurre con el santuario de Cerro Esmeralda, al mismo tiempo que, se hace necesaria una evaluación de muchos otros sitios a penas trabajados, a parte de actualizar e incrementar la actividad arqueológica en este territorio.

El Desierto de Atacama. Dentro de esta otra gran zona se encuentran las cuencas del río Loa en sus cursos Superior, Medio e Inferior a través del cual es posible acceder a la costa del Océano Pacífico, y la cuenca del Salar de Atacama, correspondiente a la hoyada intermontana dejada por las cordilleras Barros Arana y de los Andes. A este territorio comprendido entre el Loa y el Despoblado de Atacama se lo enmarca dentro de la subárea Circumpuneña, en la cual se han integrado los desarrollos culturales que bordean el Altiplano Boliviano por anbos lados de los Andes, es decir, del Desierto de Atacama, la Puna Atacameña y el extremo septentrional del Noroeste Argentino. La zona que en este caso nos interesa, corresponde a la vertiente occidental formada por las dos cuencas mencionadas.

Aquí se observa una situación intermedia a la de los Valles Occidentales chilenos y la Pampa del Tamarugal, por cuanto la investigación se ha desarrollado en las tierras altas de ambas cuencas a través del trabajo en sitios específicos que en algunos casos ha derivado en interpretaciones generales; pero al mismo tiempo, se observa una intención 
integradora de los datos producto de estudios sistemáticos que ya han entregado publicaciones más temáticas. En este sentido se cuenta con un abundante registro de evidencias, puesto que se han desarrollado prospecciones en casi todos los sectores, permitiendo reconstruir gran parte de la senda que siguió el dominio inca en su penetración al territorio Atacameño. Lo anterior se traduce en un conocimiento bastante completo de las tierras altas y en específico de la red vial ; en cambio la costa, desembocadura del río Loa y el curso inferior de éste han recibido un tratamiento más esporádico.

Para efectos de nuestra revisión adquieren importancia los reconocimientos enfocados en el camino imperial a partir del sector Kollahuasi en el extremo norte de la zona (LYNCH Y NúNEZZ, 1994), en las nacientes del Loa y todo su curso Alto (CASTRO, 1992 ; Berenguer, 1994 ; Cornejo, 1995), uniendo Cupo, Turi y Caspana de acuerdo a las informaciones generadas por G. Le Paige (CASTRO Y VARELA, 1997), y el de San Pedro que sigue por el Despoblado de Atacama en dirección a Copiapó (NúNez, P., 1981 ; NIEMEYER Y RIVERA, 1983 ; LYNCH, 1995-96). En suma, es evidente que existe una intensión por -desarrollar estudios temáticos aunque más bien impulsados por una ya larga tradición de arqueología regional con centros, respectivamente, a lo largo del río Loa y San Pedro de Atacama. Esta dinámica también ha permitido construir un registro donde se cuentan, además del camino, poblados tremendamente intervenidos por el Inka, por ejemplo, Turi en el Loa (Aldunate, 1991) y Catarpe en el Salar (LyNCH y NúNEEZ, Op. cit.), e instalaciones directamente relacionadas con la explotación minera (p.e., CASTRO, Op. cit.; AdAN Y URIBE, 1997) y agrícola (p.e., NúÑEZ, P., 1991 l y y). Por otra parte, se agregan varios tambos antes del río Loa, por ejemplo, el de Kollaguasi, así como a lo largo de éste entre los que sobresalen Cerro Colorado también conocido como Sirawe o Bramador (CASTRo, Op. cit., Berenguer, Op. cit.), Incahuasi cerca de Conchi (CORnEJo, 1995), Cerro Verde en Caspana (CASTRO, Op. cit. ; ADÁN Y URIBE, 1995 y 1997), y todos los que siguen el camino del Despoblado entre el mismo San Pedro y Copiapó. De éstos destacamos el de Licancabur a los pies del volcán homónimo (Le PalGe, 1978), y los de Peine, Meteorito, Aguada de Puquios, Vaquillas, etc. (Niemeyer y Rivera, Op. cit.). Conjuntamente, se cuenta con una serie de registros arquitectónicos que han probado la existencia de un estilo inca de construir, caracterizado más allá de la presencia de los tambos por edificios públicos tan importantes como una "kallanka" en el poblado de Turi (CASTRO et al., 1991), un "ushnu" en la instalación minera de Cerro Verde (CASTRO, Op. cit.; ; AdÁn y URIBE, Op. cit.), depósitos o "collcas" en Incahuasi y Vega Salada de Caspana también asociados a explotación mineral (ADÁN y URIBE, $O p$. cit.), y plataformas de los santuarios de altura que se cuentan en buena cantidad como lo demuestra, sólo en el Salar, su presencia en Licancabur, Pullar, Yariques, Colorado y Quimal (Le Palge, 1978). Asimismo, a lo largo del camino imperial se reconocen pequeñas estructuras bautizadas como "chasquihuasi" con atributos constructivos incaicos que complementan el panorama, junto a la presencia de obras agrohidráulicas como las de Socaire que de igual modo han sido asociadas a la expansión del Tawantinsuyu (NúNEz, P., Op. cit.).

Por lo anterior, a diferencia de otros materiales la arquitectura ha recibido gran atención por los investigadores a partir de la cual se han realizado importantes sistematizaciones (RAFFino, 1981 ; CASTRO et al., Op. cit.), algunas de ellas capaces de señalar con mayor precisión las contribuciones del Inka a una práctica bastante conocida por los habitantes del Desierto de Atacama (CAstro et al., Op. cit.), al mismo tiempo que entregan una buena herramienta metodológica. Por el contrario, la alfareria de todos esos 
sitios, la textilería de cementerios y santuarios, la metalurgia u otros materiales han sido escasamente considerados en estudios monográficos de la ergología incaica a pesar contar con buenas muestras incluso del camino, ya que gracias a lo extenso de los tramos recorridos se ha recuperado una gran cantidad y variedad de materiales (Niemeyer y Rivera, Op. cit.).

De este modo, basados en la enorme variedad de sitios con arquitectura resalta una marcada impronta inca en la vertiente occidental circumpuneña que, sin embargo, a penas se percibe en los restos muebles de la expansión. De hecho, es tan rico su registro que en sitios como Turi este aspecto ha permitido sugerir que la arquitectura es un medio de expresión simbólica de la conquista de estos territorios (CASTRo, Op. cit.; Gallardo et al. 1995); lo cual, paralelamente había sido propuesto para el resto del Loa Superior (CORNEJO, 1995). De esta manera, la investigación ha intentado introducirse en otros ámbitos de la cultura material permitiendo incluso vislumbrar conductas que tienen referentes en las "mitologías" oficiales del Tawantinsuyu, registradas en la literatura etnohistórica. En este sentido, en términos metodológicos el trabajo arqueológico en este territorio ha hecho uso de la data etnohistórica como también se le reconoce a los colegas de Arica, pero además, últimamente la etnografía se ha ocupado en forma sistemática en ciertos temas, por ejemplo, para el reconocimiento en terreno del camino como para su interpretación (CASTRO Y VARELA, 1997). A esto hay que añadir algunos esfuerzos por sistematizar el arte rupestre que se ha encontrado asociado a estos vestigios, a pesar de que aún no contamos con muchos trabajos publicados (GALLARDO Y VILCHES, 1995).

No obstante, la explicación de los hechos le ha dado tanto importancia a los artefactos muebles sobretodo a la cerámica y dentro de ésta especialmente a lo decorado, por lo cual se tiende a minimizar la presencia inca en el Desierto de Atacama lo que resulta contradictorio con las evidencias arquitectónicas mencionadas y la variedad de sitios que delatan su paso. De este modo, por lo común su dominio se considera "indirecto" al igual que en los Valles Occidentales y la Pampa del Tamarugal, mediatizado por entidades altiplánicas :

"El dominio de los Incas en Atacama se puede considerar "oblicuo", por cuanto al parecer no llegaron directamente desde el $\mathrm{Cuzco}$, sino desde sus centros administrativos del altiplano. Desde aquí junto con colonias aymaraes descendieron hasta estos oasis y controlaron a las autoridades políticas establecidas en los pukaras..." (BITTMAN et al., 1978 : p. 51$)$.

Esta tesis, como fácilmente se aprecia es una variación de la ocupada en las otras regiones analizadas, la cual es compartida por la mayoría de las publicaciones. Sin embargo, en este caso también existen interpretaciones alternativas dentro y fuera de la misma línea trazada por la anterior. Así, por ejemplo, existe la idea de que sí hubo un dominio "más directo" incluso militar, pues hay evidencias de imposición violenta como es el caso de la construcción de la "kallanka" de Turi sobre antiguas construcciones locales (SILVA, 1985) ; una ocupación con integración diferencial de las poblaciones, especialmente las que se encuentran en la ruta del camino imperial (CORNEJO, 1995), y la idea de una presencia cultural directa sugerida por las eficacia simbólica de las oposiciones materiales (p. e., Gallardo et al., Op. cit.). Esta última proposición aún en proceso (AdÁn Y URIBE, 1997). Pero además existen ciertas incoherencias en la interpretación tradicional, ya que en ningún momento quedan claras las evidencias pertenecientes a los grupos altiplánicos, excepto por uno que otro fragmento del tipo cerámico Saxamar (Cfr. NúÑ̇z, L., 1984).

Al mismo tiempo, a la hora de las explicaciones quedan prácticamente olvidados 
los restos del Loa Medio, Inferior y de su desembocadura aún cuando se sabe de importantes sitios en ellos como los poblados, cementerios y sitios ceremoniales de "muro y caja" de Chiuchiu y Lasana (Pollard, 1970), el cementerio Poniente de Quillagua (Aguero et $a l ., 1995)$ y el ya mencionado Caleta Huelén (NúÑE, L., 1971), todos los cuales exhiben improntas del imperio.

En definitiva, ${ }^{+}$odo el potencial de la materialidad presentada no siempre se compadece con la aplicación tan mecánica del citado modelo ( $C f r$. NUÑEZ Y Dillehiay, $1995[1978])$.

El Norte Chico.Una vez atravesado el Despoblado de Atacama nos encontramos en las tierras de Copiapó, las que tradicionalmente se han entendido como el inicio del espacio "Diaguita Chileno" (Sensu Latcham, 1928). En éste los ríos se incrementan hacia el sur como también en algo las precipitaciones y de nuevo alcanzan al mar, dejando territorios interfluviales en cuyos valles se desarrollaron las poblaciones prehispánicas. De ellos, el primero es Copiapó donde desde hace algunos años se ha configurado una entidad cultural distinta a la entendida como propiamente Diaguita. La cultura Copiapó tendría su apogeo durante el periodo de expansión del Tawantinsuyu y sería contemporánea a aquella poseedora de un desarrollo más profundo en el tiempo que se extendería hasta el río Choapa, un poco antes de Chile Central.

En primer lugar, tenemos que el valle de Copiapó ha sido uno de los más investigados y su información se ha sistematizado creando importantes síntesis regionales (Niemeyer, 1985-86 ; Niemeyer et al., 1991 y 1997). A partir de ellas se pueden apreciar unos cinco sectores que involucran, en primer lugar, al propio valle de Copiapó, la quebrada de Paipote y sus afluentes después y, por último la quebrada Carrizalillo, los ríos Jorquera y Pulido. En este sentido, se registran vestigios incaicos en los cursos Medio y Alto de la cuenca, configurándose como el espacio mejor investigado de esta parte del Norte Chico, aún cuando sabemos que también existen ocupaciones en la costa de Chañaral, Caldera y Huasco. Estas, por lo general, están relacionadas con cementerios que se extienden incluso hasta Tal-Tal pero que, prácticamente, han recibido un tratamiento sólo ocasional $(C f r$. LATCHAM, 1928).

Volviendo a Copiapó, se nota una concentración de sitios con arquitectura en el curso superior de la cuenca entre los que destacan a parte de este valle, aquellos de los ríos Jorquera y Pulido, lo cual parece tener directa relación con los pasos de la cordillera de los Andes hacia la vertiente oriental. De este modo, en el Copiapó mismo existe un extenso registro de "tamberías" como el de La Ollita y Pircas Coloradas junto a pasos como el de Pircas Negras, por otra parte, a los asentamientos de La Puerta, Punta Brava, Hornitos y el bastante monumental centro metalúrgico de Viña del Cerro (NiEMEYER et al., 1983 y 1984). En tanto en el río Pulido, además de otros, se cuenta con uno de los sitios más importantes correspondiente al asentamiento de Iglesia Colorada, donde se distinguen construcciones que van más allá de un simple tambo (p.e., "kallankas"), asociadas a un sector de enterramientos y un poblado. Debido a esta situación el sector ha sido sugerido cono el Copiapó o, más bien, Copayapu original (CASTILlo, 1997). Finalmente, en el valle del Jorquera se encuentran otras importantes tamberías como La Guardia y cementerios de considerable extensión como el de Las Estacas o Castaño que recién se han comenzado a investigar, pues fueron descubierto hace muy poco producto de Estudios de Impacto Ambiental en la zona. En suma, tenemos una serie de yacimientos que pueden ser agrupados 
en poblados, tambos, instalaciones metalúrgicas y cementerios a los cuales se unen los santuarios de altura del mismo volcán Copiapó y el del Jotabeche (REINHARD, 1991) y los tramos del camino imperial (Iribarren y Bergholz, 1972-73; Stehberg y CABEZA, 199 la y b; RAFFINo, 1995).

A este variado panorama de sitios se debe entonces la existencia de una buena cantidad de materiales cerámicos, metalúrgicos, líticos y textiles gracias a la conservación en las altas cumbres. Es decir, la ergología del Inka en este territorio varía más en la cantidad que en la calidad de los materiales aún cuando aquí es evidente el predominio de la cerámica a la hora de la interpretación. Esto, porque existe una alta producción local de cerámica decorada con pintura presente en todas las clases de sitios, mucha adoptando rasgos incaicos. Sin embargo, también se mantienen las identidades, ya que es posible reconocer el tipo Copiapó Negro sobre Rojo y el Diaguita especialmente en su variedad denominada Punta Brava (NiemeYer, Op. cit.), de las manifestaciones Diaguita-Inca e Inca Cuzqueño, de los cuales el primero es dominante en casi todos los casos.

Fuera de los sectores costeros mencionados más arriba algunos aspectos de este mismo registro se tienden a repetir hacia el norte de Copiapó, por ejemplo en la instalación minera de El Salvador (IRIBARREN, 1972-73), y también más al sur como ocurre con el cementerio Alto del Carmen en las cercanías de Vallenar (NiEMEYER, 1971), el que exhibe el material cerámico más cuzqueño encontrado en tierras "Diaguitas". En cambio, adentrándose en dicho territorio la investigación no ha sido tan actualizada y sistemática como en la cuenca del Copiapó y, por otra parte, muchos de los hallazgos se han integrado al estudio de sitios "Diaguita Chilenos". Por ello, existen muy pocos trabajos enfocados a la problemática inca a pesar de haberse recuperado en ellos una enorme cantidad de alfarería de esta filiación. Este es el caso del cementerio Fundo Coquimbo y Punta de Piedra en el valle del Elqui (Cornely, 19 ), el poblado de Las Terneras en su curso superior, el cementerio Pisco Control en Ovalle (González, P., 1995), el centro minero de Huana en el valle del río Limarí (NIEMEYER, 1970) y los santuarios de altura de los cerros Las Tórtolas y Doña Ana (AMPuERo, 1989).

En suma, tenemos un registro arqueológico que si bien comprende una gran variedad de vestigios y diversidad de sitios, la interpretación se basa en casi todos los casos en las expresiones alfareras que se identifican a lo largo de este territorio (CORNELY, 19 ; IRIBARREN, 1975 y s/f), a partir de las cuales se propone un eficiente y al mismo tiempo armonioso proceso de "aculturación" que ha apoyado la idea de un dominio directo de la' zona :

"En esta fase [III] se encuentra la transculturación inca-diaguita, aparentemente sin un momento de transición entre ambas. Este hecho impulsa a proponer la idea de que la conquista incaica debió ser tan rápida como la fusión cultural. A todos los autores les ha llamado la atención, en especial en lo que se refiere a la cerámica, la extraordinaria capacidad de los artesanos diaguitas para adoptar y adaptar las formas, decoración y técnica introducidas por los incas en la cerámica local" (AMPUERo, 1989 : p. 285).

De este modo, se detecta una concordancia que no vimos en el Norte Grande entre los restos inmuebles y los muebles -arquitectura y cerámica- que apoya una explicación como la anterior, sin embargo, a partir de la misma alfarería se han identificado otras situaciones que complican el modelo tradicional actualmente en boga. En primer lugar, en Copiapó nos enfrentamos a un grupo que pareciera ser distinto al Diaguita de más al sur representado por la cerámica Copiapó Negro sobre Rojo y, por otra parte gracias a 
recientes estudios de la alfarería Diaguita se ha distinguido una presencia significativa de estilos alfareros provenientes del Noroeste Argentino especificamente La Paya, y del Altiplano Meridional correspondiente a Saxamar (GoNZÁLEZ, P., 1995a y b). Esto nos indica que si seguimos el argumento cerámico utilizado hasta ahora, también puede inferirse que el dominio fue efectuado por "colonias" originarias de Argentina y Bolivia, las que incluso en el caso de las argentinas lograrían cierta influencia en la artesanía Diaguita debido a la adopción de ciertos motivos La Paya (González, P., Op. cit.). Pero, por otro lado, también se observa la adopción de patrones "cuzqueños" que indicarían la fuerza del Tawantinsuyu en la zona; no obstante, la distribución diferencial de la cerámica Inca-Diaguita respecto a la local, sugiriéndonos que dicha aculturación tampoco fue tan igualitaria.

Por último, uno de lo problemas más interesantes de la zona radica en las fechas de la expansión, en especial de Copiapó, pues la ausencia de su tipo cerámico más al sur, la asociación en casi todos los sitios de éste con la alfarería Inca-Diaguita y las dataciones absolutas obtenidas principalmente en Chile Central, invitan a algunos investigadores a proponer algo que M. Uhle ya había sospechado mucho antes (1908). Esto es, que el proceso expansivo se habría desarrollado de sur a norte (CASTILLO, 1997), es decir, los contingentes incaicos se habrían movilizado primero por el borde oriental conquistando el Noroeste y Centro-oeste Argentino. Asi sorteaban las dificultades del Despoblado de Atacama para ingresar luego a Chile conquistando a los grupos Diaguitas y finalmente los de Copiapó, controlando los pasos transcordilleranos en cuanto vía de acceso a Argentina (RAFFino, Op. cit.) y como fuente de aprovisionamiento sobretodo forrajero, después del cruce del Despoblado. Lo interesante de esta propuesta radica, además de las contribuciones hechas al registro arqueológico de Copiapó, en una nueva perspectiva de las vías utilizadas por la expansión, al mismo tiempo que introduce la discusión sobre los fechados tempranos que se han comenzado a obtener en el norte (p.e., MuÑOz, 1991 ; ALDUNATE, 1991) y centro del país (RodRígueZ Y GONZÁLEZ, 1991).

Con todo, es evidente una mayor integración de los datos de Copiapó en relación al resto del Norte Chico el que por su parte aún requiere mayor sistematización de sus datos, así como nuevas investigaciones, las cuales sólo se han visto favorecidas por el reconocimiento del camino imperial hasta el río Choapa (STEHBERG, 1991 y 1995 ; SteHBerg y CABeZa, Op. cit. ; Stehberg y Carvajal, 1987).

Chile Central Esta parte del país se extiende desde el río Choapa al Cachapoal, pudiéndose distinguir que los valles transversales del Norte Chico dan paso a otros más anchos debido a la presencia de la Depresión Longitudinal, con una mayor cantidad de precipitaciones que generan un clima mediterráneo con cuatro estaciones bien marcadas y, asimismo, con ríos que concentran una cantidad de recursos hídricos mucho mayor a los anteriores. Por lo tanto, los paisajes desérticos de más al norte comienzan a ser desplazados, apareciendo tres importantes cuencas correspondientes a los ríos Aconcagua, Mapocho-Maipo y Cachapoal. Sus desarrollos mantienen una unidad cultural durante el período conocido como agroalfarero tardío que ha sido englobada bajo la denominación de Cultura Aconcagua, la cual tampoco está exenta de particularidades locales como veremos a continuación.

Desde el Choapa ya se comienza a registrar la avanzada inca a través del reconocimiento de algunos tramos del camino (STEHBERG, 1995 ; Stehberg et al., 198586 ), el cual se ha trazado hasta su llegada al actual centro de Santiago, por lo menos hipotéticamente (RIVERA Y HYSLOP, 1984). 
En otro ámbito, si bien existe una larga tradición de investigación en el curso del Aconcagua son pocos los estudios arqueológicos enfocados al problema inca, los que se reducen en esencia al rescate de cementerios como El Triunfo (DURÁN Y COROS, 1991) y el "enclave" de Cerro La Cruz (Rodriguez et al., 1991). Sin embargo, la importancia de ambos es considerable, por ejemplo, en el primero se reconocen enterramientos en bóvedas, lo cual parece transformarse en una práctica común en Chile Central durante el período del dominio incaico. Mientras que en el segundo caso, se cuenta con otra clásica práctica de este territorio relacionada con asentamientos habitacionales llamados "fortalezas" o "pukaras", porque se encuentran emplazados en las mesetas de algunos cerros y amurallados (otros se encuentran mencionados en STEHBERG, 1995). En Cerro La Cruz, particularmente, resalta la presencia de una considerable cantidad de metalurgia representada por cinceles y punzones que parecen ser del mismo estilo que los detectados en el Norte Chico y Grande, configurando así un patrón de explotación minera semejante al de esas zonas, en este caso ligado con probabilidad al centro inca que según la etnohistoria, se hallaría en Quillota (STEHBERG, 1995).

En ambos yacimientos abunda la cerámica Inca-Diaguita a la cual se une la local donde, entre otros, se distinguen los tipos Aconcagua Salmón propio de ésta cuenca, y la Aconcagua Rojo Engobado característica de la cuenca de Santiago o Mapocho-Maipo.

Un panorama semejante ofrece este último valle, aunque aquí los cementerios son predominantes, pues también se reconoce la existencia de asentamientos como Cerro Mercachas y Chena al norte y sur, respectivamente, de la cuenca (STHEBERG, 1976 y 1995). De hecho, el "pukara" de Chena fue considerado por mucho tiempo el vestigio más meridional de la expansión del Tawantinsuyu, y con ello se estableció una frontera al norte del río Maule, la cual ha sido muy defendida desde la historia. Dicha postura sustentaría que el dominio incaico efectivo no habría sobrepasado más allá de Santiago debido a la tenaz resistencia de los grupos "mapuches" del sur (SILVA, 1983, 1985-86 y 1986).

Respecto a los cementerios, en particular destacan el de La Reina correspondiente en realidad a unas cuantas tumbas de individuos de "élite" inca, pues han sido sepultados en cámaras y acompañados por un ajuar que incluía alfarería, metales $\mathrm{y}$, es posible, que hasta andas o "rampas" (Mostny, 1947). En este sentido, nos encontramos frente a un contexto mucho más puro que los de la cuenca del Aconcagua, no obstante la existencia otros cementerios, por ejemplo los de Quilicura (STEHBERG, 1976 ; GonZÁlez y Rodríguez, 1991), donde de nuevo se registran los estilos de cerámica conocidos como Inca, IncaDiaguita (La Paya) y Aconcagua; en tanto las sepulturas otra vez muestran estructuras abovedadas (González y RodRiguez, Op. cit.). Asimismo, se observan cementerios más locales en cuanto se distingue entre las ofrendas sólo alfarería Inca-Aconcagua como en Plaza Italia, ya en Santiago mismo (STEHBERG, 1987). Este último, se relaciona con toda una serie de sitios funerarios en el centro de la ciudad como los de Marcoleta y Compañía, de los cuales se tienen escasas referencias debido a que han sido arrasados por el proceso urbanizador de la capital del país (STEhBERG, Op. cit.).

A esta importante concentración de yacimientos de connotación ceremonial se deben agregar los santuarios de altura en territorio nacional, ubicados en el Cerro El Plomo y en el Peladeros (Mostny, 1957; Medina, A., et al., 1976 ; CabezA, 1986 ; CabezA y Tudela, 1987). De éstos, el más famoso sin duda es El Plomo por el sacrificio humano que se encontró en una de las estructuras de la cumbre en excelentes condiciones de conservación, gracias a las cuales se pudo recuperar casi intacto el cuerpo de un niño e incluso determinar 
que su lugar de origen estaría en el altiplano del Collasuyu (Mostny, Op. cit. ; Quevedo y DuRÁN, 1992). Junto con ello, las ruinas mismas y el resto de los materiales recuperados entre los que destacan sobretodo textiles, metalurgia, restos orgánicos (uñas, pelo, vegetales, plumas) y objetos de "spondylus", han dado origen a múltiples estudios monográficos (CABeza, Op. cit. ; Medna, A., et al., Op. cit. ; Mostny, Op. cit.). Todos ellos concluyen la existencia de grupos "incas" debido a que esta práctica llamada "capacocha" se encontraba restringida al manejo estatal, lo cual parece ser concordante con que los fragmentos de cerámica del sitio hayan sido asignados como no-locales, del mismo modo que los de Cerro Peladeros (CABEZA y Tudela, Op. cit.). En este sentido, se sugiere una sacralización de este espacio en cuanto última conquista, ya que se trata del santuario más austral ( $\mathrm{C}_{\mathrm{ABEZA}}$, Op. cit. ; Quevedo y Durán, Op. cit.).

En muchos aspectos, lo anterior se encuentra relativizado por las últimas investigaciones en la cuenca del Cachapoal, es decir, adentrándonos a la zona Centro Sur conocida como de los "promaucaes", donde se han descubierto los vestigios más 'meridionales del Inka que los ya descritos. Estos siguen un patrón suficientemente similar como para ser integrados a la dinámica de las cuencas de Aconcagua y Santiago, por cuanto se ha identificado la fortaleza del Cerro Grande de La Compañía o del Inga (PLANELLA y Stehberg, 1994 ; Planella et al., 1991), y los entierros de Cerro Tren-Tren en Doñihue (StehBERG y RodRiguez, 1995). El primero de ellos exhibe el mismo patrón ya descrito, es decir, compuesto por recintos amurallados en la meseta de un cerro, a lo que en este caso específico se suma, entre otros, la existencia de depósitos o collcas. Por su parte, lu alfarería mantiene los nexos Inca-Diaguita y Aconcagua. En tanto, Cerro Tren-Tren aporta con otro tipo de contextos que si bien eran conocidos a través de los cementerios de Santiago, guardaría cierta relación con las prácticas detectadas en los santuarios de altura combinada con "creencias" de los grupos mapuches. Esto, porque para los investigadores existe una sugerente relación entre el nombre del cerro, muy conocido en la mitología mapuche, la ubicación de una cámara funeraria en él y el entierro secundario de los restos de algunos niños con ofrendas lnca locales. En este sentido, sería probable un proceso de aculturación de la zona denotado simbólicamente, como pudo ser en escala mucho mayor la incorporación de Santiago al Tawantinsuyu a través del sacrificio de El Plomo.

En definitiva, resulta muy interesante que en Chile Central existan grandes avances en el estudio de este tema configurando un panorama mucho más complejo de la expansión del imperio, el cual hasta ahora había sido interpretado como "pobre", probablemente porque la explicaciónha derivado más de la historia que de la arqueología misma (MEDINA, J. T., 1882 ; Silva, 1985):

"...en la zona comprendida entre los ríos Aconcagua y Maipo, tampoco se visualizan las bodegas para almacenar productos agrícolas, textiles, armas o artesanías locales. Hay, no obstante, cementerios típicamente incaicos [...] Es decir, habiendo claras evidencias de la presencia inca en estas regiones, la estructura propiamente estatal apenas se vislumbra. Sostuvimos que la dominación aparecía muy tenue comparada con testimonios provenientes de la conquista del núcleo andino (Silva, 1978). Ahora pensamos que esa difusa visión del aparato estatal podría explicarse por el hecho de que estos territorios constituían enclaves personales del monarca ; que no fueron conquistados en su integridad sino que en forma selectiva, apropiándose de sectores muy definidos por sus recursos económicos..." (Silva, Op. cit. : p. 330).

En cambio, el desarrollo que ha experimentado la disciplina en los últimos tiempos, 
se traduce junto con el incremento de la ergología incaica, en la aparición de opiniones más críticas en relación, por ejemplo, al monumentalismo arquitectónico como indicador de la presencia estatal (GonzÁLEz, C., 1996), o la existencia de patrones culturales foráneos que se observan en las prácticas funerarias (GONZȦLEZ, C., 1998). Todo ello redunda en que no es tan manifiesto el interés de un "monarca" por acrecentar sus arcas, sino más bien se perfila una estrategia estatal de incorporación donde las conductas ceremoniales como en todo el Tawantinsuyu, son utilizadas por su eficacia simbólica en este proceso. Por lo tanto, lo que estamos notando en Chile Central corresponde a un avance en los mismos términos de más al norte debido a que encontramos arquitectura, caminos, santuarios, metalurgia, cerámica y textiles identificables como incas, quedando las etapas iniciales de la conquista cubiertas por la ocupación posterior y, probablemente, evidenciadas más al sur. Esto coincide con que las dataciones absolutas retroceden la presencia inca hacia el 1390 d.C. en el Aconcagua (Rodriguez y GonZÁlez, Op. cit.), abriendo un nuevo campo de discusión al respecto que debe ser superado con más estudios, puesto que los trabajos en Cerro de La Compañía han arrojado fechas más clásicas, es decir, sobre I 450 d.C.

El. Sur de Chile y el problema de La Araucania. Hemos introducido dentro de esta zona el territorio comprendido al sur del Cachapoal, el cual también es conocido entre éste y el río Maule como Centro Sur, mientras que del Itata al Golfo del Reloncaví es considerado como el espacio mapuche por esencia, llamado La Araucanía a partir de la invasión española. En general, estas tierras se caracterizan por el aumento progresivo de las precipitaciones que genera ambientes boscosos y hasta selváticos donde se desarrolla una entidad cultural que tiende a desligarse de los patrones más septentrionales.

Por su parte, el tema del Inka ha sido considerado comúnmente por los investigadores, por lo menos pioneros como J. T. Medina (1882), M. Uhle (1908) y Latcham (1928), a partir de lo cual existe un consenso respecto a considerar esta zona como la frontera meridional del imperio (RAFFINO Y STEHBERG, 1997), aunque más bien derivado de la historia que de la arqueología. En este sentido, el problema de la frontera ha sido el más estudiado (SILVA, 1983, 195-86 y 1986 ; TÉLLEZ, 1990), sin mayores aportes sobre la cultura material de esta situación ; mientras que el arqueológico, basado en las ideas de R. Latcham, se restringe a unos pocos estudios sobre la alfarería (DILLEHAY y GoRdon, 1988).

Con todo, es evidente que hasta el momento no se registra la ergología del resto de los territorios, compuesta por poblados, tambos, centros metalúrgicos, tramos del camino, santuarios de altura, etc., de hecho tampoco se registra alfarería de morfología inca. Sin embargo, en este caso, basados en la presencia de decoración pintada de los estilos $\mathrm{El}$ Vergel y Valdivia, pertenecientes a los desarrollos agroalfareros tardío y mapuche histórico, junto a información etnơhïstórica y etnográfica, se ha intentado demostrar la presencia Inca en la Araucanía (GoRdón y DILlehay, Op. cil.):

“...en la región de nuestro interés, existían dos tipos de fronteras incaicas, diferentes, pero complementarias, 1) una frontera geopolítica exclusiva y definida, que delimitaba la ocupación territorial en alguna parte del país entre la ciudad de Santiago y el río Maipo o el río Maule, en cuyas orillas el avance de los incas fue detenido por los araucanos y 2) una frontera geoeconómica inclusiva, militarmente no ocupada y no contenida dentro de las fronteras formalizadas del Imperio Incaico. Esta región se ubicaba en forma de islas formando un archipiélago de variadas actividades estatales dispersas, al sur de los ríos Maipo y Maule, en el interior del territorio araucano" (Op. cit. : p. 215). 
Sin duda, lo anterior resulta ser una sugerencia interesante, sin embargo, conspira contra ello, la ausencia de investigaciones en terreno, ya que, muchos datos utilizados en su construcción son utilizados muy ligeramente. En suma, se trata de un espacio virgen en cuanto este tema requiere ser estudiado, pues es lo más probable que sea en algún punto de él donde se encuentra la frontera austral del Tawantinsuyu. La cual parece acercarse cada vez más hacia el Maule como afirmaba el cronista Garcilaso.

\section{Material dE ESTUdio, TEMÁTICAS, INTERPRETACIÓN Y MODELOS}

Gracias a la revisión realizada vemos que la investigación del Inca en Chile ha considerado en sus estudios la espacialidad de los vestigios, la red vial, la arquitectura de los sitios, las instalaciones metalúrgicas, las obras agrohidráulicas, los santuarios de altura, la funebria, el arte rupestre, la alfarería, la textilería y los metales. Por lo tanto, este registro podemos dividirlo en aspectos inmuebles y muebles, de los cuales queremos destacar aquellos que ' más nos han llamado la atención, pues a partir de ellos han surgidos temas, líneas de investigación, tratamiento de los materiales y modelos de interpretación.

\section{TEMÁTICAS, MATERIAL DE ESTUDIO Y SU TRATAMIENTO}

Aspectos inmuebles Dentro de éstos sin duda, es recurrente el tratamiento del "inqañam, capacñam" o camino del Inka, el cual ha sido arqueológica y sistemáticamente reconocido en la Sierra de Arica, el Alto Loa, la localidad de Turi, Caspana y el Despoblado de Atacama en el Norte Grande; los tramos y pasos transandinos del Huasco, Elqui, Limarí, Combarbalá, Illapel y Choapa en el Norte Chico hasta Putaendo, desde donde se entraría a Chile Central hasta, en términos más hipotéticos, el Cachapoal.

De todos los casos a los que hicimos referencia la labor de R. Stehberg es destacable, a parte de su aporte empírico, por su continuidad en el tiempo convirtiendo el tema en una verdadera línea de trabajo, lo cual le ha permitido postular la existencia de un "camino Inca Longitudinal Altoandino", por lo menos para el Norte Chico. El trazado de éste aprovecharía una falla geológica de la cordillera, la cual fluctúa de norte a sur entre los 4.000 y $600 \mathrm{msnm}$, permitiéndole acceder a los valles bajos del oeste y a una serie de pasos transcordilleranos que conectan con la vertiente oriental de los Andes y, por lo tanto, con el "camino Longitudinal Argentino". Este mismo emplazamiento, según el autor, habría facilitado la expansión del imperio, ya que a través de dicha vialidad se controlaría un ancestral movimiento poblacional hacia las tierras altas consideradas fuentes de subsistencia, por ejemplo para el ganado, y por sus conexiones con el Noroeste y Centro-oeste Argentino (1995). En este sentido, el trabajo de Stehberg motiva a reflexionar sobre el concepto de vialidad como parte de la política estatal, por cuanto existe una serie de conocimientos comprometidos en su construcción que van más allá de las características formales de la red. Por lo mismo, también son interesantes los alcances metodológicos de su experiencia.

Otros aportes interesantes sobretodo en términos metodológicos son los de $\mathrm{H}$. Niemeyer y colaboradores en su exploración del camino inca del Despoblado de Atacama (1983), ya que contribuyen con un acucioso registro de datos, de la misma manera que el reconocimiento previo de Iribarren y Bergholz en este mismo tramo (1972-73), o el caso de C. Santoro para la Sierra de Arica (1983). Asimismo, resulta importante la experiencia que se ha comenzado a practicar en el Loa Superior, donde se combina la exploración en 
terreno con la historia oral sobre los incas (CASTRO Y VARELA, 1997), en una zona con evidencias de rutas pre y post-incaicas de larga data que señalan la necesidad de ser consideradas como lo precisa otro estudio del camino (LyNCH, 1995-96).

Relacionado con lo anterior, se ha estudiado la espacialidad de la ocupación Inca en cuanto distribución de los sitios y las características de éstos. Uno de los casos más interesante es el desarrollado por L. Cornejo para el Loa Superior (1995), quien postula que la presencia Inca en la región se distribuye siguiendo el trazado de su red vial longitudinal, demostrando un dominio enfocado en el interés específico por los recursos minerales de las poblaciones locales como lo demostraría la existencia de un "ushnu" en Cerro Verde (Caspana). Por estas razones, las instalaciones estatales establecidas a lo largo del camino y los poblados que se atravesaban a éste serían los lugares donde se registraría el mayor impacto del Tawantinsuyu, a diferencia de los espacios laterales que habrían sido menos afectados. En consecuencia, el impacto del imperio se manifestaría en un eje nortesur que uniría especialmente las áreas de afloramiento de minerales en su ruta hacia el sur, sobretodo cobre, adquiriendo su dominio un carácter "indirecto" debido a la ausencia, según el autor, de artesanias al modo cuzqueño. En cambio, por su carácter funcional tal dominio se evidenciaría en las construcciones que en el caso de los poblados afectaría los espacios más "sagrados" de las comunidades como ocuire con las "chullpa" o adoratorios del pukara de Turi, algunas de las cuales serían eliminadas para levantar una "kallanka", posible templo, y su "cancha", ambas estructuras inmediatamente conectadas con el camino imperial.

En suma, se ha llevado a cabo una profunda reflexión de la espacialidad del registro arqueológico, confirmando un estrecho vínculo entre camino, instalaciones, explotación minera y "religiosidad" como un conjunto significativo privilegiado por el dominio incaico en esta región. Sin embargo, en primer lugar se desconoce la situación transversal, la cual es relegada a lo local a pesar de que se han detectado importantes manifestaciones incaicas en los oasis de Chiuchiu y Lasana en el Loa Medio (PolLard, 1980[1972]; SpaHni, 1963 y 1964), en Quillagua en el Loa Inferior (AGUero et al., 1997) y Caleta Huelén-23 en la desembocadura de éste (NúÑEz, L., 1971; SPHANI, 1967); cuyos cementerios y sitios de "culto" apoyan que la expansión del Tawantinsuyu sigue hacia la costa, en cierto sentido, por la misma via "religiosa". No obstante, es claro que falta aumentar las investigaciones al respecto en el resto del Loa, pues éstas han sido mucho más esporádicas en relación a las del curso superior.

Un elemento que ya ha sido señalado reiteradamente es la arquitectura, puesto que se cuenta con bastante registro de ella desde Arica hasta el Cachapoal. Sin embargo, son los estudios del Pukara de Turi en el Loa Superior, los que destacan por su contribución en términos metodológicos e interpretativos, ya que en el resto de los casos el trabajo se reduce a detalladas descripciones. En Turi, V. Castro y colaboradores (1991), entre los cuales se cuenta un arquitecto, aportan con un instrumento de recolección de datos, conceptos, definiciones y un lenguaje adecuados para el tratamiento de las construcciones, gracias a to cual la información puede ser vaciada en bases de datos estadisticamente analizables, porque los mismos estudios del pukara se basan en muestreos programados del sitio (CASTRO Y Cornejo, 1990). De esta manera se ha llegado a diferenciar la arquitectura foránea de la local, al mismo tiempo que detectar el planeamiento y la noción de "urbanismo" reflejado por cada una de las entidades, dentro de lo cual destaca la planificación selectiva de los incas. Debido a la utilidad de tales herramientas, éstas se han continuado usando en las actuales 
investigaciones de la localidad de Caspana. Un antecedente semejante se observa en el trabajo de R. Raffino (1981), si bien su experiencia de terreno se centra en Argentina ha aportado con una valiosa reflexión sobre las características de este aspecto en Chile. De hecho, éste concluye un fuerte impacto del imperio en la región del Loa Superior, producto de la identificación de rasgos "de primer orden" en la arquitectura de los sitios del período (p.e., kallanka, canchas, collcas, ushnu, tambos, etc.), es decir aquellos que tienen un referente indiscutible con el diseño arquitectural del Cuzco.

Pero, tampoco podemos dejar de señalar el aporte realizado anteriormente por $F$. Piazza junto a los colegas Santoro y Muñoz en Arica (1981), gracias al cual fue posible reconstruir la aldea de Az-15 en Pampa Alto Ramírez, de cuya experiencia de nuevo resalta la planificación urbana de los espacios construidos. Asimismo, es interesante notar que los distintos arqueólogos han generado un importante banco de datos sobre este tema como lo demuestran las experiencias de H. Niemeyer en todos sus estudios, los de R. Stehberg en el Norte Chico y Chile Central (1995) a los que se unen los de M. T. Planella y colaboradores 'en la fortaleza de Cerro de la Compañía en el Cachapoal (1991 y 1994) y la reflexión de $O$. Silva para Tarapacá (1994). Todo esto nos indica la importancia que tiene y, por lo tanto, que requiere el tema de la arquitectura a la hora de tratar el problema del Inka, a pesar de que ésta no tenga el monumentalismo que se observa en los Andes Centrales como lo discute C. González (1996).

Respecto a su importancia, queremos destacar el simbolismo que se ha intentado identificar en la recurrencia de la arquitectura, el cual se ha vislumbrado a partir de los emplazamientos, orientaciones cardinales y rasgos asociados a las construcciones (entierros, ofrendas, etc.), por ejemplo, en los santuarios de altura, "ushnus" y ciertos edificios. Uno de ellos ha sido el trabajo de Gallardo y colaboradores (1995) que, otra vez en Turi, han sugerido la existencia de conceptos fundacionales del dominio incaico reconocidos en la documentación etnohistórica del Tawantinsuyu (crónicas y diccionarios), analogables en su materialidad al emplazamiento de sus edificios, los cimientos de piedra de éstos, la preparación de los pisos, las conductas de limpieza de ellos, el entierro de trozos de palos cavadores y restos humanos, los cuales se reparten de manera diferencial, en una relación opuesta y no detectada en los contextos locales. En suma, se postula que como parte de la estrategia de la expansión se replicarían en los espacios conquistados ciertos actos ocurridos en el Cuzco, con lo cual no sólo se fundarían construcciones, sino también el dominio del Inka. Por lo mismo, dichos actos adquieren un carácter político simbólicamente expresado a través del cual el espacio local es rearticulado de acuerdo a un orden y propietario nuevos.

En una línea semejante, aunque totalmente independiente son los trabajos desarrollados por algunos de los estudiosos de los santuarios de altura, uno de los aspectos inmuebles más peculiares y propios hasta ahora de la porción meridional del imperio, por lo general, relacionada con el Collasuyu. Así, en un contexto simbólico por excelencia han atisbado la relación entre dominio y materialidad aunque sin darle un carácter político propiamente tal, sino más bien religioso. Este resulta ser el caso del santuario del Cerro El Plomo en Santiago, el cual desde su descubrimiento ha sido motivo de monografias como las de G. Mostny (1957), A. Medina y colaboradores (1976) y la memoria de título de A. Cabeza (1986), además de un artículo de S. Quevedo y E. Durán que deriva de la comparación con otros contextos similares, correspondientes a los del Aconcagua y el Toro en los Andes argentinos (1992). Todos ellos, más o menos coinciden en señalar que dicha práctica se relaciona con expresiones de la religión estatal, de lo cual se deriva la 
presencia "directa" de funcionarios estatales que sobretodo en el caso de aquellos que presentan sacrificios humanos o capacocha, implicarían convertir algunas cumbres locales en deidades a modo de "huacas", incorporándolas de esta manera al panteón local y con ello los territorios y poblaciones asociadas (CABEZA, 1984 y Op. cit.; QuEVEDO y DURÁN, Op. cit.). Sin duda, en estos trabajos también ha influido en forma relevante la documentación etnohistórica existente para el imperio.

Pero también lo anterior ha significado desarrollar una línea de investigación denominada Arqueología de Alta Montaña, la cual se ha llevado a cabo en San Pedro de Atacama, Copiapó, y Chile Central (CAbeZA, Op. cit.; Checura. 1977; Le Paige, 1978; Medina, A., et al., Op. cit.). Sin embargo, aún ha sido intermitentemente implementada excepto por las experiencias de J. Reinhard (p.e., Vid. 1991), aún cuando sus investigaciones se insertan dentro de un programa que va más allá de Chile.

Otro aspecto a través del cual se ha intentado entender el simbolismo de los vestigios incaicos dice relación con la funebria. No obstante, a pesar de una considerable cantidad de cementerios o enterramientos excavados, tales estudios caen dentro de la categoría de trabajos específicos (CAstillo, 1998; Cornely, 19; Durán y Coros, 1991; FoCaCci, 1981; 1947, Niemeyer 1963 y 1971; Stehberg, 1976; Stehberg y Morales, 1987; Stehberg y Rodríguez, 1995). Para efectos de esta revisión, en la práctica sólo contamos con investigaciones de sitios funerarios de Chile Central que derivan en una reflexión más profunda sobre lo que significaron estas prácticas y los patrones que se concluyen de ellas (González y Rodriguez, 1991; Stehberg y Rodriguez, 1995). Por ejemplo, se ha tratado el concepto de "machay" o sepulturas en estructuras de piedra que remiten a las cuevas donde se habría originado la humanidad asociada al Inka (GONZÁLEZ, C., 1998). Específicamente, esta discusión se centra en la asignación cultural que se adjudica a dichos patrones, puesto que se relacionan al medio y modo a través del cual se habría realizado la conquista de esta parte de Chile. Por este lado, a partir de dichos contextos se ha concluido la presencia de cuzqueños, mitimaes o colonias diaguita-incas, poblaciones locales Aconcagua aculturadas, otras en tal proceso como las más sureñas y algunas ya hispano-indígenas (mapuches). Todo ello enmarcado dentro del problema de la ausencia de una cronología que dé cuenta de los cambios y continuidades poblacionales (GonzÁlez, C., Op. cit.). Mientras que, por otra parte se ha hecho una sugerente propuesta relacionada con el sincretismo entre creencias y prácticas incaicas y mapuches en momentos casi históricos, basada en la analogía entre el emplazamiento de un enterratorio secundario de infantes, las características constructivas. de él y las ofrendas con la mitología de dicha población que es tratado como parte de una estrategia del Tawantinsuyu de acercamiento a aquellos (StehBERG y Rodríglez, Op. cit.).

Finalmente, dentro de los aspectos inmuebles de la arqueología del Inka en Chile se encuentran los estudios de instalaciones metalúrgicas, agricolas y expresiones de arte rupestre, los cuales en general han recibido una atención mucho menos recurrente y más bien enfocada a sitios o localidades específicas. A pesar de que siempre se encuentran referencias bastante numerosas de este tipo de actividades, se hayan insertas dentro de otras problemáticas o aspectos del problema (Cfr. Ál.VAREZ, 1992-93, IrIBARrEN, 1972-73). En cuanto modelo de trabajo de centros mineros se encuentra el sitio Viña del Cerro en e] valle de Copiapó, el cual no sólo ha sido analizado sino que también se ha restaurado para su conservación y puesta en valor tal como lo demuestran los trabajos de H. Niemeyer y colaboradores (1983 y 1984). Aquí cabe destacar las excelentes excavaciones que permitieron recuperar las evidencias necesarias para comprobar la existencia de "huayras" 
u hornos donde se fundía el mineral, además de toda la serie relacionada con la cadena metalúrigca entre las que se encuentran crisoles, moldes, objetos, escoria, etc., con lo cual se logró comprobar que se trataba de una instalación metalúrgica de filiación incaica, quizás una de las más intactas del Tawantinsuyu. Sin embargo, nos encontramos con una línea de trabajo esencialmente descriptiva. En cambio, menos riguroso pero más sugerente, es L. Alvarez al proponer una determinación de los grupos culturales comprometidos en esta actividad productiva detectada en la desembocadura de la quebrada de Camarones (Op. cit.). En su caso, por una parte confirma la presencia de dichas labores en la costa tarapaqueña, pero además de sus expresiones técnicas directas e indirectas así como de los objetos formatizados, es capaz de sugerir la existencia de una minería local, altiplánicainca e inca imperial. Sin duda, se trata de una experiencia novedosa que puede ser continuada con el apoyo de análisis metalogénicos.

En tanto, la actividad agrícola asociada al Inka ha merecido una mayor atención en el Norte Grande, territorio en el cual se reconoce una larga tradición agrohidráulica -compartida con el resto de los Andes Centrales, manifiesta en terrazas o andenes de cultivo y sistemas de canales. De este modo, encontramos referencias sobre el tema en los Valles Occidentales chilenos desde la costa hasta la sierra (ÁlvAREZ, 1995 ; SANTORO et al., 1987), en el Loa (CASTRO y Alliende, 1991) y en el Salar de Atacama, siendo especialmente en este último donde $P$. Núñez ha desarrollado un verdadero programa de investigación centrado en la localidad de Socaire. En dos de sus publicaciones al respecto (1991 a y b), su trabajo comprende la revisión de algunos antecedentes sobre la agricultura en el norte chileno en la época del Tawantinsuyu, se llevan a cabo reconocimientos en terreno que consideran la calidad de los suelos y el potencial de las aguas, las características de los canales y su flujo, su distribución en hectáreas, etc., y el conocimiento de la población local al respecto junto a información documental sobre el mismo. Además, haciendo cálculos de hectáreas cutivables ha logrado estimar la capacidad de dichos sistemas $y$, consecuentemente la población a la cual habría sustentado, de lo que se desprende una intención del estado incaico por maximizar la productividad entre los 2.300 y $3.700 \mathrm{msnm}$. Es decir, aprovechando las cualidades diferenciales que ofrece la micro-verticalidad de la zona.

Paralelamente, en Arica se han Ilegado a establecer algunas conclusiones semejantes sobretodo en cuanto al aumento de la productividad agrícola, aunque al contrario del caso anterior derivan más de aportes reflexivos que de una recolección rigurosa de datos en terreno. Es así que, para lo tramos bajos de estos Valles Occidentales se postula que existiría una diferencia radical entre los espacios ocupados por la población local y los del Inka, pues este último privilegiaría los valles con aguas salobres o "salados" como Lluta y Camarones antes no explotados ni ocupados por lo primeros. Quienes, por el contrario, lo habrían hecho intensamente en los valles "dulces" como el de Azapa en Chile (Álvarez, Op. cit.). De acuerdo a ello, la población local habría preferido estos últimos porque así tenía el acceso a una mayor variedad de cultivos a pesar del considerable riesgo que significaban las características de la cuenca, por ejemplo, caudal discontinuo, violentas crecidas estivales, plagas, etc. Mientras que por las propiedades opuestas, el imperio se habría instalado en los otros valles con el propósito de tener cosechas por lo menos dos veces al año, las que se restringirian a las especies tolerantes a las aguas saladas de preferencia el maíz, correspondiente al monocultivo más importante para el estado y sus compromisos redistributivos como ceremoniales (bebida y comida). Lo anterior estaría demostrado por la escasez de restos incaicos en Azapa y la gran recurrencia de éstos en 
Lluta y Camarones. De hecho, en el caso del primero se han recuperado gran cantidad de "kipus", los cordeles directamente relacionados con la contabilidad estatal, y se ha registrado el mayor número de depósitos subterráneos (ca. 700), señalándo el interés inca por el almacenamiento.

Un proceso semejante parecería ocurrir en la Sierra de Arica aunque la discusión se centra más bien en la asignación "étnica" de las entidades culturales comprometidas, pues se postula una ampliación y complejización de los sistemas de regadío preexistentes, llevados a cabo por la población local pero dirigidos por grupos altiplánicos al servicio de Tawantinsuyu (SANTORo et al., Op. cit.).

En cuanto al arte rupestre, notamos muy poco interés a pesar de que pareciera existir mucha claridad al momento de reconocerlo. En este sentido, hasta ahora sólo dos trabajos nos ofrecen una sistematización de este conocimiento, ambos realizados en el Loa Superior. En uno de ellos (BERENGUer et al., 1981), se ha elaborado una secuencia del arte rupestre registrado en el Alto Loa usando un análisis que compara dichas expresiones con los iconos de otros soportes como la alfarería, textilería, metalurgia y otros, gracias a lo cual se definieron los diseños que en esa zona caracterizarían la presencia del lnka. Por su parte Gallardo y Vilches. esta vez en Turi, tienen el mérito de centrarse en un sitio fuertemente impactado por éste, el cual resulta ser interesante también porque dicho arte aparece asociado al espacio donde se desarrolló la vida cotidiana de las poblaciones bajo su dominio. Con esta muestra se pudo establecer la importancia de la imagen del camélido rígido de dos patas y orejas hacia adelante o atrás durante la ocupación incaica, puesto que la mayor parte se concentra en la cercanía de las construcciones del Tawantinsuyu y aledaño al camino imperial que pasa por un costado del poblado. Al mismo tiempo, se pudo definir la existencia de una expresión rupestre local en la cual también aparece representado el camélido, pero con una construcción más areal y dentro del predominio de un estilo geométrico paralelo que se distribuye hacia el centro del "pukara". En este sentido, además de comprobar una idea generalizada en la arqueología chilena y del Collasuyu (RAFFINo, 1981), la del "camélido rígido" como indicador de la presencia inca, esta experiencia es interesante en términos de las relaciones que se pueden establecer gracias al tratamiento tanto estilístico como estadístico de tales manifestaciones.

Por último, sólo queremos señalar Ja preocupación existente por el tema de la frontera, desarrollada en la zona Centro-Sur del pais, el cual ha sido tratado como ya hemos dicho más desde la historia que de la arqueología (Cfr. RAFFino y STEHBERG, 1997). Dicha preocupación ha generado una enorme cantidad de artículos por parte de $O$. Silva (1977-78, 1983, 1985-86, 1986) y últimamente por E. Téllez (1990), quienes se refieren a la resistencia ofrecida por las poblaciones de lengua mapuche en el territorio comprendido por los ríos Cachapoal y Biobío. Estas incluso Ilegan a ser tratadas étnicamente como promaucaes y picones, defendiendo así la idea de que este fue "límite austral" del imperio en oposición a las afirmaciones de personajes como Garcilaso de la Vega que lo sitúa en el Maule. Evidentemente, la información proviene de las fuentes documentales españolas por lo cual no existe todavía una comprobación de este límite que, de todas maneras, puede ser discutido si consideramos que nuevas investigaciones como la de la fortaleza del Cerro La Compañía en el Cachapoal, combinando arqueología y etnohistoria han desplazado ese límite desde el Maipo a esta otra cuenca (Planella et al., 1994 y 1991). De hecho, desde nuestra disciplina también se ha postulado que este sector más que un límite sería una zona de frontera, definida como un espacio privilegiado para el encuentro cultural. No 
obstante, la materialidad usada en esta hipótesis se relaciona con los aspectos muebles o mobiliares a los que nos referimos en seguida (DILLEHAY y GORDON, 1984).

Aspectos muebles. En este ámbito de la investigación, la materialidad mobiliar incaica ha sido estudiada desde la alfarería, por supuesto, la metalurgia y la textilería, aunque dentro de un tratamiento por lo general esencialmente descriptivo.

En el caso de la alfarería, como se preveía desde los trabajos de R. Latcham (1928), la principal contribución que se deriva del análisis de una enorme cantidad de material fragmentario y entero recuperado a lo largo del territorio chileno conquistado, se relaciona con la identificación de una morfología cerámica casi invariable en toda la extensión de este espacio. Y, por otro lado, se concluye una estilística iconográfica que varía desde la ausencia total de decoración pintada hasta los estilos híbridos conocidos como Diaguita-Inca, Inca-diaguita-aconcagua, Inca-Aconcagua, además de aquellos que han sido catalogados de Inca Cuzqueño, Imperial, Provincial o Altiplánico. Cada una de estas denominaciones es utilizada en forma bastante libre y poco precisa debido a la carencia - de estudios monográficos sobre este material, lo cual ha llevado a mantener en el tiempo una serie de supuestos sin una base analítica muy sólida. Creemos que esto se debe y redunda en una falta de consensos entre los especialistas que por lo general no consideran la situación local y se restringen al modelo formal generado por J. H. Rowe para el Cuzco (1969[1944]). Por lo mismo, sus conclusiones son de corto alcance y poco profundas.

Los ejemplares incaicos, siguiendo a Rowe, se identificarían por sus pastas muy compactas y homogéneas que podriamos llamar "coladas", y porque morfológicamente corresponden a los cántaros llamados "aríbalos", las escudillas hondas y planas con modelados ornitomorfos (el cual a veces se reduce a un par de protúberos en lados opuestos del borde o la cabeza es reemplazada por un asa), jarros de cuellos hiperboloides con asas adheridas al labio o cuerpo de la vasija de manera diagonal, y ollas con pedestal también con asa diagonal. De todas éstas, sólo las ollas no presentarían decoración pintada aunque sí modelada, muy poco estudiada en nuestro país. En cuanto a la primera clase de decoración, existe una tendencia a considerarla policroma aún cuando sabemos que el mismo autor define otras variantes, por ejemplo, alisadas, monocromas, bicromas, etc. (Op. cit.). Dentro del estilo, los motivos considerados o presentados en Chile como propios del Cuzco serían los triángulos en hileras, una figura compuesta por un pequeño círculo unido a tres líneas paralelas que adquiere la forma de una espiga y los rombos, todos ellos en colores negro, rojo, blanco y/u ocre.

Si utilizamos el trabajo de Rowe como referente, en el Norte Grande nos encontramos con una escasa presencia de cerámica de estilo cuzqueño o imperial en cuanto alfareria policroma de pastas coladas. Lo anterior está en directa relación con la importancia que pudo la decoración pintada en la misma capital del imperio, situación que no se ha evaluado hasta el momento, ya que las muestras analizadas por el autor provienen de sus sondeos en los alrededores del Cuzco y de la colección recuperada de las tumbas de Machu Picchu por H. Bingham y G. F. Eaton (Op. cit.), de las cuales fueron seriadas sólo las decoradas para establecer la secuencia histórico-cultural de la zona. Pero, el mayor problema para el Norte Grande es que además no se cuenta con un exponente Inca-local al modo del Norte Chico y Chile Central, lo cual en oposición a estas zonas es interpretado como la ausencia de un proceso de aculturación entre ambas entidades debido a que no existió una intención porque la conquista fuera no sólo política, sino también cultural (BITTMAN et al., 1978). 
Con todo, específicamente para la zona de Arica los trabajos de P. Dauelsberg (1959 en adelante) que consideraron los aportes previos de C. Munizaga (1957), distinguieron una serie de variantes de manifestaciones incaicas de las cuales sobresale el tipo Saxamar o IncaPacajes como les denominaron respectivamente. Estas son escudillas rojas sobre las que se pinta en negro una serie de figuras de camélidos muy estilizados como los que se describen para el arte rupestre y se les adjudica un origen en el altiplano circumtitikaka, puesto que ahí fueron reconocidas por S. Rydén asociadas al Inka (1947). Esto junto con la apreciación de que los sitios del período exhiben ejemplares de estilo cerámico post-Tiwanku, ha llevado a señalar para esta zona que el dominio del Tawantinsuyu fue de la mano de los grupos altiplánicos que de acuerdo a la información etnohistórica se encontraban usufructuando de estas tierras con las poblaciones locales a la manera propuesta por J. Murra (MuÑOz, 1996; Muñoz y Chacama, 1991; Muñoz et al., 1987; Santoro et al. Op. cit.). Por supuesto, esta interpretación es muy sugerente, sin embargo, ha dejado de lado el problema de la situación alfarera local que cuenta con una tradición de cerámica con y sin decoración, tanto pintada como modelada, de mucha profundidad temporal (URIBE, 1995, 1996 y 1997).

Por su parte, la explicación para el resto de Tarapacá y la zona del Desierto de Atacama no es muy diferente, ya que cuenta con aún menos estudios al respecto debido a que, al parecer, ha primado el énfasis en las cerámicas decoradas, sin tomar en cuenta que ésta es una práctica ajena a la tradición alfarera de ambas zonas donde ésta es absolutamente monocroma ( Vid. AdÁN y URIBE, 1995; AgÜERo et al. 1997; URIBE, 1996). No obstante, igualmente se registran piezas de morfología incaica y en particular en el desierto de Atacama se atisba la existencia de una industria local de éstas que privilegia sobretodo las categorías morfo-funcionales que no existen en su alfarería, por ejemplo los jarros (URIBE, Op. cit.). A ello se unen de modo bien recurrente expresiones híbridas relacionadas con el Noroeste Argentino y, en particular, con los centros de Yavi y La Paya ( $O p$. cit.). Sin embargo, todavía no se cuenta con una monografía al respecto que considere una muestra más amplia y referentes de distintas zonas, así como estudios especializados que permitan determinar el origen de las materias primas utilizadas (Cfr. V ARELA, 1992). En este sentido, han primado más las interpretaciones que los análisis, para nuestro gusto, producto de una lectura muy ligera de la documentación etnohistórica que le otorga a la cerámica un carácter casi étnico (SANTORO et al., Op. cit.).

Por otra parte, es evidente la existencia de una situación opuesta desde Copiapó al sur donde la producción alfarera local con la expansión del Tawantinsuyu se encuentran intimamente ligados, adquiriendo su máxima expresión en la simbiosis denominada Diaguita-inca o Inca-diaguita. Desde muy temprano en la investigación del Norte Chico se ha tocado el tema como lo demuestran los trabajos de F. Cornely (1947) y J. Iribarren (1975), los cuales ya nos asombran por la gran cantidad de piezas que a primera vista combinan formas incaicas con iconografia Diaguita Chilena, recuperadas en los también numerosos cementerios de la época. Por lo mismo y a falta de otros materiales, creemos que aquí se han realizado esfuerzos bastante interesantes por sistematizar e interpretar los datos de esta clase como resulta del trabajo de P. González (1995a y b), aunque una gran mayoría se mantiene dentro de una práctica más bien descriptiva. No obstante, con anterioridad trabajos como éstos, entre los que se cuentan los de H. Niemeyer, contribuyeron a diferenciar los cambios en las populares escudillas Diaguita clásicas, a identificar la existencia de un tipo independiente denominado Copiapó Negro sobre Rojo para Copiapó y un subtipo del Diaguita-inca bautizado como Punta Brava. 
Por su lado, P. González ha hecho un ejercicio donde se combinan la aplicación de un marco teórico de corriente estructuralista, colecciones de museo y la información contextuạl -antropología física, alfarería y otros- del cementerio diaguita-inca Pisco Control de La Serena. Por estas razones, su estudio tiene el mérito de aportar con una reflexión teórico-métodológica, es uno de lo pocos que usa estadística, rescata la información de material poco documentado impulsando su puesta en valor y ha sido capaz de proporcionar un análisis contextual que muy pocos de los sitios funerarios de la época han recibido. De esta manera, en la cerámica de la región de Coquimbo ha logrado distinguir por ejemplo, que las piezas consignadas como incaicas se asocian a las formas tradicionales como aríbalos. jarros, escudillas y ollas como las ya mencionadas, en las cuales las decoraciones que en primera instancia han sido entendidas como diaguitas, en su mayoría serían "cuzqueñas" y por lo mismo expresan patrones de cuatripartición en su decoración (p.e., el rombo escalerado) que no son tan recurrentes en el estilo local, en esencia más heterogéneo y repetitivo (p.e., la greca escalerada). Y en consecuencia, que la proporción de diseños diaguita-inca es mucho menos significativa de lo que tradicionalmente se asumía. A esto se une el hecho que los estilos incaico, diaguita-incaico y diaguita clásico que se mantiene del período anterior tienden a presentarse diferencialmente en los contextos funerarios, a parte que las piezas de estilo local se encuentran restringidas a las formas diaguita. Al mismo tiempo, la imagen del felino y los elementos que lo constituyen se incrementan, todo lo cual es asumido como parte del impacto y penetración cultural que realiza el Tawantinsuyu en la zona. Sin embargo, más allá de las connotaciones simbólicas del trabajo nos parece igualmente rescatable la identificación de distintas esferas de interacción participando del proceso, ya que no sólo se reconoce la introducción de elementos incaicos en el estilo diaguita, sino también de otros provenientes del altiplano a través del reconocimiento de iconografía Saxamar y, en especial, del Noroeste Argentino por medio del estilo Inca-La Paya. Por lo tanto, se observa que en la configuración del diaguita-inca se encuentran participando varias entidades que en realidad van disminuyendo la importancia de lo local o, mejor dicho, desplazándolo. Por lo tanto, sería más riguroso hablar de un estilo Inca-diaguita.

En cambio, en el centro de Chile las investigaciones arqueológicas sobre el tema de la alfarería y el Inka vuelven a adquirir un carácter descriptivo, de escasa profundidad analítica al contrario de lo que ocurre para los periodos agro-alfareros previos, correspondientes a las tradiciones tempranas y la cultura Aconcagua, en este caso, directamente afectada por la expansión. Como se puede apreciar, los estudios se han centrado en la problemática local y por lo general la relación con el Tawantinsuyu ha sido identificada a través de la presencia del estilo Diaguita-inca, y en especial gracias a la identificación de otro que combina elementos aconcagua, diaguita e inca bautizado como tipo Aconcagua Trícromo Engobado (MASSONE, 1978). De acuerdo a esta situación, se supone la utilización de mitimaes diaguita-incas en la conquista de este territorio, estrategia basada en las relaciones anteriores de los diaguita chilenos con la cultura Aconcagua como se podría inferir a través del tipo Aconcagua Salmón Tricolor (Op. cit.). Sin embargo, no existe ningún estudio que evalúe cuantitativamente estas interpretaciones ni tampoco la relación de la cerámica local con las de supuesto origen foráneo, aún cuando sin mayores fundamentos se identifican piezas inca locales, imperiales o cuzqueñas. Lo anterior de nuevo contrasta con las investigaciones sobre la cultura Aconcagua, cuya alfarería ha sido tratada incluso estadísticamente. La excepción a ello lo encontramos en los intentos desarrollados por A. 
Medina (1976) y Cabeza y Tudela (1987) para los santuarios de altura de El Plomo y Cerro Peladeros, respectivamente, quienes a partir del análisis de los fragmentos concluyen la existencia de cerámica distinta a la local e incluso a las híbridas de origen diaguita y aconcagua que aparecerían en los cementerios de tiempo inca de Santiago. En cualquier caso, sí serían comparables entre los dos sitios.

En este sentido, como en el caso de la zona de La Serena a Ovalle es importante evaluar el sentido de estos préstamos estilísticos, al mismo tiempo que su verdadero peso cuantitativo en la producción local contemporánea y previa, considerando a favor que aquí los estudios de cerámica son bastante más detallados que los de más al norte.

Hacia el sur de la zona Central la situación es mucho más precaria, pues incluso no es claro el desarrollo cultural que correspondería a la época, aunque se piensa que sería una derivación del Aconcagua identificado a través de un estilo Centro-sur ya detectado con anterioridad por R. Latcham ( 1928a). El panorama cambia al ingresar en La Araucanía donde existe una historia de la investigación arqueológica un poco más larga, por lo que cuenta con una serie de estudios sobre la alfarería de los períodos temprano, tardío e histórico. Para nuestros objetivos, los únicos que han utilizado las evidencias alfareras del desarrollo tardío con el propósito de demostrar la influencia incaica en esta zona otra vez son Dillehay y Gordon (1988). Estos, sin embargo, pecan de no considerar que el origen de la cerámica con decoración pintada conocida como El Vergel y Valdivia corresponden a situaciones que no necesariamente se relacionan al Inka. En el primer caso, nos enfrentamos a una expresión del desarrollo tardío de la zona sur, especialmente detectado gracias a sus prácticas funerarias en el sector norte de ella comprendido entre las cuencas de los ríos Biobío y Cautín. Los mismos autores citados dan cuenta de fechas muy anteriores a la expansión incaica para dicha cerámica, por lo tanto asumimos que este desarrollo o por lo menos la aparición de decoración pintada en la alfarería corresponde a una prolongación de los hechos ocurridos más al norte y a ambos lados de la cordillera, pues son zonas con las cuales las poblaciones locales desde mucho antes mantuvieron relaciones (ALDUNATE, 1989). Por su parte, la cerámica Valdivia, corresponde a una expresión más característica de la porción meridional de la zona, estrechamente ligada a momentos históricos y a la configuración del actual pueblo Mapuche. No obstante, en cuanto a alfarería se refiere consideramos que ella tiene un sustrato en El Vergel, al cual se suman aportes locales y foráneos tanto indigenas como hispanos $(O p$. cit.) que aún requieren una investigación más profunda. De hecho, los motivos decorativos tienen referentes indígenas en los estilos . diaguita, aconcagua e inca, pero todavía no se han detectado las típicas vasijas de morfología en especial incaica que confirmen la penetración del Tawantinsuyu como más al norte. Con todo, concordamos con Dillehay y Gordon que esta situación podría ayudar a definir una distinción entre límites y fronteras del imperio, siendo éstas últimas un paso previo dentro de la estrategia expansionista para la conquista de un territorio. Pero reiteramos, todo esto requiere un estudio que debería considerar introducirse en la problemática previa y posterior, asi como en las relaciones con las zonas colindantes.

Por su parte la metalurgia, la textilería, la madera e incluso el material lítico dentro de una miscelánea mayor, siempre han contado con la atención de los arqueólogos aunque su tratamiento se reduce a un inventario de piezas más o menos mejor descritas y que en casos puntuales cuentan un análisis técnico adecuado pero, casi en ningún caso problematizado. Con esto nos referimos a la ausencia de tratamientos monográficos que a parte de la descripción, sistematización y análisis del material consideren comparaciones, 
análisis contextuales y elaboren síntesis que permitan identificar, por ejemplo, los elementos locales y foráneos en cada situación dada.

Para la metalurgia contamos con una gran cantidad de registros de punzones y cinceles, cuchillos con forma de medialuna o "tumis", agujas, alfileres y prendedores o "tupus", brazaletes, anillos, orejeras y diademas, artículos para la pesca (p.e., anzuelos), adornos para el pelo o "lauraques", manoplas, estatuillas de camélidos y figuras humanas femeninas y masculinas además de placas, pequeños lingotes y material fundido no formatizado. En todos ellos se ha constatado el uso de cobre, oro y plata, siendo los dos últimos los más estandarizados para la elaboración de las ofrendas depositadas en los santuarios de altura, consistentes de preferencia en las estatuillas humanas y zoomorfas. De hecho, es aquí donde la existencia de este material es más recurrente que en cualquier otro, del mismo modo como en la costa del Norte Grande aumenta la representación de instrumentos de pesca, mientras que en los centros mineros tienden a aparecer punzones, cinceles y cuchillos a parte del material derivado de la fundición. Con todo, de nuevo no ' contamos con un estudio acabado sobre el tema, el cual en términos más generales no ha sido tratado en forma muy distinta a las antiguas obras sobre metalurgia indígena chilena de R. Latcham (1936) y J. Iribarren (1964).

El caso de los textiles no es muy diferente aún cuando se registran en todo el territorio nacional conquistado a través del material de los santuarios de altura y sobretodo de los cementerios del Norte Grande, pudiéndose distinguir todo la ergología del vestuario incaico como los "uncus" o camisetas, taparrabos o "huara", "aguayos" o "Ilicllas" que son como mantas, las fajas y los "acsus" o vestidos de las mujeres. Asimismo, se pueden identificar entre estos tejidos aquellos que entran en la categoría de "cumbi" o finos y "abasca" o corrientes, u otras piezas como las aún vigentes "chuspas" o pequeñas bolsas ceremoniales en las que por lo general se llevaban las hojas de coca, los "kipus" o cordeles contables, las hondas o "warakas", etc. (Vid., p.e., CHECURA, 1977). Empero, también éstos se insertan en estudios más generales o como una mera descripción dentro de los trabajos sobre sitios incaicos.

Por último, la industria en madera y lítico se reduce a la mención ocasional de ciertos artefactos. En el caso de la madera se habla de vasos kero y cucharas en el Norte Grande (Vid., p.e., SANTORO y Ulloa, 1985 ; BitTMAN et al., 1978) ; mientras interesantes artesanías en piedra se han reconocido en el Norte Chico como son ciertas fuentes incluso con decoración zoomorfa o escenográfica, además de otros artefactos relacionados con actividades como la metalurgia donde se encuentran crisoles y moldes ( $\mathrm{Vid}$., p.e.. A MPUERO, 1989 ; CASTILLO, 1998). Por lo tanto. todos estos materiales están esperando la atención de los investigadores.

INTERPRETACIÓN Y MODELOS

De todos los aspectos tratados hasta ahora el menos desarrollado es el concerniente a los modelos explicativos de la expansión y dominio del Tawantinsuyu en Chile, aún cuando de todos los trabajos se deriva una interpretación que tiende a minimizar el impacto del imperio sobre nuestro territorio nacional, adjudicándolo a entidades intermediarias. De tal manera que desde Arica al Cachapoal se le define como un espacio marginal. Respecto a esto, creemos que uno de los problemas más graves es tomar como referente los Andes Centrales, cuyas características como el "monumentalismo" y la "espectacularidad" de sus desarrollos culturales opacan los de más al sur. Del mismo modo, el gran pionero de la arqueología 
chilena, R. Latcham atacó esta visión que en su época era atribuida a la misma expansión de los Incas. El historiador D. Barros Arana habría difundido a través de su Historia de Chile la idea de que éstos serían los responsables de la civilización de nuestro territorio, donde se encontraba una serie de poblaciones primitivas y bárbaras.

"Sin duda los indios de Chile eran entonces (a la llegada de los incas) tan bárbaros como las tribus más groseras que los conquistadores hallaron en América (P. 50).

La ocupación de una parte de Chile por los vasallos del Inca importó un gran progreso en la industria de este país. [...] Todo nos hace creer que los indios chilenos se hallaban, antes de la ocupación peruana en un estado de barbarie semejante al de muchos otros salvajes de América. (Hist. De Chile. Tomo I, pp. 68-72) " (citado por LatCham, 1928 : pp. 230-231).

Sin embargo, la arqueología le habría permitido a Latcham construirse otro panorama surgido de un quehacer propiamente empírico, donde se sucederían a través del tiempo una serie de culturas que antes de la llegada de los incas habrían domesticado animales, practicado la agricultura, producido cerámica, textiles, metales y vivirían en poblados. Razón por la cual los "peruanos" habrían sentido la necesidad de expandir sus dominios hasta aca. De este modo tenemos que, "Otros de los errores propagados por Barros Arana [...], es el que le atribuye a los incas toda la cultura de los indígenas chilenos prehispánicos" (Op. cit. : p. 230).

Latcham se opone tenazmente a esta teoría empleando una serie de argumentos que se refieren, por ejemplo, a la cronología de la expansión, restringiendo el dominio efectivo de la zona Central y el Norte de Chile entre 45 y 75 años respectivamente como límites máximos. De acuerdo a ello, pone en duda que si los indígenas chilenos eran tan salvajes, cómo en tan poco tiempo podrían haber integrado todos los adelantos traídos por el Inka.

"Hemos visto que el tiempo que duró el dominio incaico en el país era breve, del todo insuficiente para convertir a un pueblo en estado de absoluto salvajismo y babarie, como estos autores quieren pintar a los indios chilenos antes de la llegada de los incas

¿Cuáles, entonces, eran los grandes beneficios que aportaron los incas a la cultura chilena ? A nuestro ver, ninguno de gran novedad e importancia" A (Op. cit. : p. 235).

No obstante, tampoco desconoce la presencia de éstos y destaca la introducción de una estética nueva, una ampliación de la distribución de la arquitectura, mayor orden político y administrativo, la imposición de un tributo que se limita principalmente al oro que era fundido en diferentes localidades, la construcción de guarniciones y fortalezas en lugares estratégicos, e implantación de colonias de "mitimaes" en las regiones más pobladas para enseñar las costumbres y lengua del Cuzco.

Con todo, creemos que su ardua lucha por desmitificar el salvajismo de los indígenas ha tenido un peso bastante negativo en la arqueología del lnka en Chile, puesto que sus trabajos de campo nunca lo consideraron como un tema relevante en relación a los autóctonos. De esta manera, pensamos que debido a ese peso que significa este investigador para la disciplina nacional, habría contribuido en forma preponderante a esta percepción que reduce el impacto de dicha presencia en nuestro territorio. Por ejemplo, esto se refleja en otros de los pioneros como G. Mostny que, sin duda basada en Latcham, ya en la década de los '70 señala en su Prehistoria de Chile :

"La invasión y ocupación incásica en Chile fue relativamente corta. No duró más que unos 70 años en el Norte Grande y quizás sólo unos 30 años en Chile Central, al norte del Maule" (1971 : p. 163). 
A esta percepción se une por aquella misma época el impacto provocado por $\mathrm{J}$. Murra en toda la antropología y arqueología del mundo andino, correspondiente al modelo del control vertical de un máximo de pisos ecológicos surgido del análisis documental de la economía del Tawantinsuyu, el cual se hace extensivo al resto de las sociedades andinas a través de la incorporación de información etnográfica (1972, 1983[1955]). Este se ha convertido en un verdadero paradigma para la arqueología sobretodo del lnka que hacia mediados de aquella década se tradujo en Chile en la aparición de la hipótesis sobre la expansión incaica de A. Llagostera (1976). Lo anterior significó una revolución propia dentro de la disciplina, a pesar de que el mismo Llagostera no siguió profundizando el tema, pues permitió dar una explicación en términos andinos a la materialidad encontrada en los sitios con vestigios de su presencia, la cual se ha mantenido vigente hasta el día de hoy sin mayor crítica, impulsando incluso el desarrollo de modelos paralelos.

"Con esto planteamos la existencia de dos situaciones diferentes en los Andes. Una en el Macizo Central con alta frecuencia de archipiélagos étnicos y otra hacia los extremos donde las condiciones no favorecen la existencia de este modelo de organización. Frente a estas diversas realidades, la expansión incaica sufrió modificaciones cualitativas dentro de su esquema de control macro-sistémico.

En el sector central andino, partiendo de la premisa que los Incas incorporaban al Tawantinsuyu sistemas ecológicamente organizados (Llagostera, Op. cit.), encontraremos que al incorporar directamente un meso-sistema, también se estaba incorporando indirectamente parte de otro meso-sistema por intermedio de la subyugación de los archipiélagos étnicos prolíferos en el sector. [...] En cambio, en las subáreas extremas, donde no existían archipiélagos, la dominación se ha limitado sólo al valle que sufría la acción directa" (Op. cit. : p. 206).

De esta manera surge la conocida discusión si el dominio ha sido directo o indirecto, el cual se ha evaluado en términos de si la materialidad que representa al Inka es más o menos abundante y cuánto se atiene a los patrones originales del Cuzco, en especial, cerámicos. Así, tenemos que para el Norte Grande Llagostera postula que :

"El poder central del Cuzco no ejerció dominio directo sobre los actuales valles y oasis del norte de Chile. No era una región de utilidad inmediata para la gran empresa Inca; no aportaba, ni efectiva ni potencialmente, productos deseables para la política expansionista del Tawantinsuyo. Por otro lado, la región, desde tiempos preincaicos constituía el complemento archipielágico de etnías altiplánicas productoras de auquénidos, muy apreciados por el Estado Inca.

[...] Por consiguiente, su presencia en tierras tarapaqueñas, no es indicio de un dominio cuzqueño sobre la región, sino una situación circunstancial inherente al nexo islas-núcleo.

[...] Una conquista allí no tenía sentido" (Op. cit. : 211-212).

De su argumentación empírica se desprende que la presencia, en ningún caso evaluada cuantitativamente, de alfarería de origen Inca-altiplánico como la Saxamar sería el indicador diagnóstico de este proceso debido a lo cual se asume la analogía directa entre cerámica y población. Esta es Ilevada al extremo de ser planteada en términos de "colonias" al modo centro-andino aún cuando se reconoce que las evidencias alfareras aún no dan cuenta de un sistema archipielágico para esta zona.

Con todo, para los distintos arqueólogos que trabajan en el Norte Grande ha sido una interpretación muy seductora, porque no se puede desconocer la aparición de dicho 
tipo cerámico en muchos de los sitios del período. Sin embargo, no existen suficientes pruebas en la zona nuclear para asegurar que éste es el elemento identificatorio de un grupo altiplánico dominado por el Inka. Por otra parte, reiteramos que en la mayoría de los casos se ha pasado por alto un examen de la situación local o simplemente ésta ha sido interpretada en los mismos términos que para el Tawantinsuyu. Es decir, se encontrarían dominadas por grupos altiplánicos desde las cabeceras de los valles en las tierras altas, no obstante, ni en Arica ni en el desierto de Atacama percibimos que sus expresiones artesanales sean más importantes o, incluso, sometidas a un proceso de aculturación que permita distinguir entre un estilo altiplánico local y otro inca-altiplánico-local para, de esta manera, dar cuenta del impacto político de dichos "señoríos".

Específicamente para las tierras atacameñas no ha existido una mayor crítica al modelo, pues al contrario, ha sido complementado y ampliado desde otras perspectivas. Este es el caso el de L. Núñez y T. Dillehay que al elaborar un modelo más general sobre el desarrollo cultural de los Andes Meridionales (1995[1978]), la movilidad giratoria, se acercan al problema poniendo énfasis en el intercambio a través del tráfico de caravanas de llamas.

"La movilidad Inka asimiló los giros [caravániccs] preexistentes entre tierras altas y bajas, centralizando las operaciones a través de diversos modos andinos de dominio directo con presión cultural, tecnológica, social, religiosa y económica ; o indirecto, por medio del manipuleo de las instituciones, señoríos y modalidades regionales de traslados de bienes y uso de excedente social" (Op. cit. : p. 128).

De esta manera, los autores postulan para el Norte Grande que los incas descubren la eficiencia de la movilidad preexistente entre señorios de tierras altas y bajas, por lo cual en primer lugar se dedican a administrar las cabeceras o ejes altiplánicos de mayor prestigio a los que estarían en la práctica subordinadas las poblaciones locales.

"Ejerce así un dominio "oblicuo" sobre los Señoríos periféricos al altiplano y los propiamente transpuneños. No enfatiza aquí presión cultural por cuanto sus guarniciones eran más productivas que militares, estableciendo aldeas-ejes funcionalmente distintas a las locales, con población altiplánica y funcionarios cuzqueños encargados del manejo burocrático y sobreproductivo" (Op. cit. : p. 129).

En suma, se repite en esta interpretación una sobrevaloración de lo "altiplánico" en nuestro territorio como aparato clave para la expansión que si bien existe desde épocas inmemoriales ejerciendo una evidente influencia, ésta no parece traducirse en alguna clase de "dominio", excepto en los momentos de las expansiones de importantes entidades como Tiwanaku y el mismo Tawantinsuyu. A parte de que todo se vuelve a reducir al tema de la alfarería. Donde, por otro lado, se recalca la ausencia del impacto cultural a partir de la ausencia de artesanías de origen cuzqueño. Sin embargo, excepto por la cerámica, en ningún momento quedan claras cuáles serían las altiplánicas y su impacto en la producción local, al mismo tiempo que tampoco nada se sabe en específico de los bienes locales que llegarían a los centros de los ejes de intercambio privilegiados por el imperio.

La situación contraria es establecida por los autores citados para el Norte Chico, donde Llagostera había percibido que,

"Aquí [región de los valles transversales de Atacama y Coquimbo]se pierde totalmente el nexo preincaico con los Andes Centrales. No existe un sustrato anterior al Inca -como el caso de las islas altiplánicas nortinas- que amortigüe el desplazamiento expansivo del Cuzco" (Op. cit. : p. 212). 
Debido a esto, en sectores extremos del Tawantinsuyu como los mencionados, los incas habrían desarrollado un dominio directo,

"La explicación la encontramos en el hecho que los grupos autóctonos no practicaban el esquema archipielágico, razón por la cual, los incas, tuvieron que ejercer control, acá y acullá, del cordón montañoso, en forma separada, sometiendo directamente a las etnías de cada localidad y plasmando en ellas una nueva expresión que definimos como Inca Local, la que, sin duda, necesita de una evaluación diferencial en cada uno de los valles en que se detecta su presencia" (Op. cit. : p. 213).

De acuerdo a esta premisa, se explica el surgimiento de definidos estilos cerámicos en la zonas diaguitas chilena y argentina como la expresión de la conquista de los grupos locales por medio de los ejércitos incaicos y la aplicación de un programa de instauración de los patrones cuzqueños a tales poblaciones. Núñez y Dillehay (1995[1978]), son más explícitos y plantean que como las instituciones altiplánicas previas no ejercieron sus prácticas de complementariedad de recursos, los incas debieron operar en forma directa, con presión cultural y militar sostenida destinadas a neutralizar la imagen política de señorios como el Diaguita. No obstante, nos parece que un panorama tan violento no tiene aún un referente material muy consagrado y, por otro lado, ya se ha sugerido que en la expansión hacia esta zona habrían colaborado otras entidades culturales debido a lo cual se pudo estar aplicando un sistema muy cercano al de la verticalidad. Esta vez basado en las conexiones de complementariedad preexistentes entre los grupos involucrados como, en este caso, pueden ser los del Noroeste Argentino.

En definitiva, las interpretaciones y modelos analizados por nosotros dan cuenta de una falta de integración de muchos otros datos, pues como hemos visto, existe una mayor cantidad de ellos que rebasa a la cerámica, la cual hasta ahora se ha convertido en el principal indicador de los modos de dominio ejercidos por el Tawantinsuyu en Chile.

Por su parte la historia también se ha referido al tema a través de los estudios de O. Silva, quien lo ha tratado en forma constante, permitiéndole postular los motivos de la expansión a Chile creando un verdadero modelo interpretativo, más allá de los intereses por la minería y la agricultura que más o menos todos los trabajos recalcan. Sus estudios en Chile Central le permitieron concluir que:

"...la cuenca de Santiago presenta una serie de vacíos estructurales con respecto a la organización introducida por los incas en sus dominios, situación que nos induce a pensar que se trataba de una región colonizada para el rey y no para el estado. El motivo determinante de ello pudo ser la necesidad personal del monarca de forjarse su propia hacienda e incrementar su contingente se servidores perpetuos..." (1978 : p. 237).

En ese caso, los vacíos estructurales se refieren a una difusa visión del aparato imperial o, mejor dicho, que habiendo claras evidencias de la presencia inca en estas regiones, el estado a penas se vislumbra por la falta en especial de las bodegas para almacenar productos agrícolas, textiles, armas o artesanías locales, las cuales para el autor remitirían a las funciones de dicho aparato relacionadas con la "mita" o trabajo por turno rotativo.

Al mismo tiempo, esto indicaría una etapa previa de la conquista, explicada a través de una diferenciación entre lo que él llama "rentas reales" y "rentas estatales". Con ello se refiere al modo que seguían los emperadores incaicos para obtener los medios y de esa manera mantener su mando frente al estado, puesto que al momento de asumir el cargo en primer lugar debían asegurarse entradas propias debido a que el anterior gobernante se llevaba las suyas hasta la muerte. Lo anterior por otra parte, también explica una expansión 
tan rápida del imperio, pues cada uno de ellos debía sustentar desde cero todo el funcionamiento del aparato estatal, de modo tal que se recurría a la conquista de nuevos territorios para obtener mano de obra y bienes. "El nuevo Inca debía, pues, en primer lugar, forjarse su propia hacienda apropiándose de tierras, yacimientos y servidores. Estos le pertenecían a título personal..." (Silva, 1981 : p. 328).

Posteriormente a este proceso y una vez consolidado su gobierno, dicho territorio sería obligado a cumplir con los requerimientos propiamente del estado como la aplicación de la "mita" en labores que ya expresarían cierto grado de aculturación de la población dominada.

Aunque su propuesta nos resulta muy interesante, el autor no ha considerado que dicho registro puede variar en la medida que aumenta la investigación como lo han demostrado los últimos estudios en Chile Central, donde ha aparecido una serie de vestigios que permiten postular la existencia de patrones ya conocidos para más al norte. En este sentido, las bases empíricas para probar la situación propuesta son mucho más débiles que las de Llagostera. Y, por lo mismo, creemos que las ideas de Silva entre los arqueólogos no alcanzan a tener la popularidad y la vigencia del modelo de aquél.

\section{Palabras finales}

Para terminar nuestra revisión de la arqueología del Inka en Chile, en breves palabras quisiéramos destacar algunos aspectos de ella que nos han llamado profundamente la atención y que con seguridad corresponden a algunas de sus características.

En primer lugar, concluimos que con el tiempo se ha generado una enorme cantidad de datos relacionados con la expansión del Tawantinsuyu a gran parte de este territorio, gracias al carácter intrínsecamente descriptivo de nuestra disciplina. Lo anterior redunda en que dicho registro se distribuye de manera cada vez más homogénea entre Arica y el Cachapoal debido al avance de los estudios en el Norte Chico y en especial de Chile Central, lo cual permitiría un tratamiento comparativo de los vestigios. No obstante, esto no se relaciona con la ejecución de verdaderos programas de investigación que aborden el problema de manera específica, los cuales en la práctica casi no se han desarrollado. De hecho, hasta ahora no contamos con trabajos monográficos y obras de síntesis que intenten dar una visión global del problema. Por supuesto, esto contrasta con la cantidad de los restos de la presencia inca que, al mismo tiempo, implican una gran diversidad y calidad dé los materiales que ha derivado en el tratamiento de distintos temas. Pero que no han alcanzado a desarrollar, excepto por el "camino", líneas de investigación.

Por lo tanto, a nuestro juicio existen tantos datos que se hace necesario una revaluación del problema y una puesta al día del estudio de su cultura material que considere los análisis técnicos especializados, estilísticos, comparativos, contextuales, espaciales y cronológicos, muchos de ellos sobre una base cuantitativa más sólida en la elección de muestras y el tratamiento estadístico de los materiales.

Similar reflexión surge al prestar atención a los aspectos interpretativos y los modelos que se han elaborado para explicar la expansión, donde se nota una mínima valoración del registro con que contamos, probablemente influenciado por el monumentalismo y espectacularidad de los Andes centrales que no tenemos más al sur. A ello se une la propagación de la idea que el impacto del Tawantinsuyu en nuestro territorio fue mucho menor que alli, debido a su tardía y corta incorporación al imperio como a la 
ausencia de desarrollos culturales complejos que le interesaran a éste, lo cual ha terminado por definir a nuestra área como marginal (Cfr. RAFFINO Y STEHBERG, 1997).

Pero contradictoriamente, también se han aplicado de manera muy mecánica modelos propios de los Andes Centrales para explicar el dominio ejercido aquí que, sin mayor crítica posterior afirman la existencia de sistemas archipielágicos (Sensu MurRA, 1972 y 1983 [1955]), en la práctica, a partir sólo de los restos cerámicos que se convertirían en los medios a través de los cuales aquello se llevó a cabo. Con todo, ellos no dejan de tener una gran cuota de originalidad, a pesar de que sus bases empíricas son muy restringidas. Como ya lo decíamos, en general éstas se reducen a la cerámica la cual es considerada equivalente a los grupos comprometidos en el proceso expansionista, otorgándole un carácter casi étnico. Sin duda, lo anterior, deriva de una época durante la cual la arqueología recién comenzaba su desarrollo profesional, pero después de dos décadas de trabajo incesante se debe reclamar una mayor rigurosidad que vaya más allá de lo descriptivo como lo demuestran algunas de las experiencias ya realizadas. Empero, aún se nota una ausencia de crítica constructiva, imaginación, atrevimiento y originalidad, basadas en un detallado y completo tratamiento de las evidencias en los términos técnicos, estilísticos, contextuales, cronológicos, etc. a los que hacíamos mención más arriba.

La perspectiva que a lo largo de esta revisión hemos desarrollado no es para decir que todo lo hecho está malo, por el contrario, tiene el propósito de recordar y avisar a los colegas con cuánta cantidad, diversidad y calidad de datos contamos. Tal situación amerita una sistematización de los materiales y una evaluación de su tratamiento e interpretación tanto a la luz de la arqueología misma como de la etnohistoria y la etnografía andinas. Creemos que de esta manera podemos motivar a buscar ciertos consensos analíticos, conceptuales y explicativos que culminen en la tan necesaria obra monográfica de sintesis que nos abra los horizontes para superar los estudios meramente descriptivos.

Particularmente, nos damos cuenta de la existencia de problemáticas urgentes por abordar como el debate cronológico que antes se agotaba en la secuencia de J. Rowe para el Cuzco (1969[1944]), donde se consideraba que Túpac Yupanqui habría comenzado la conquista de este territorio alrededor de 1470, hoy cuestionado por una serie de dataciones absolutas que sugieren que dicho proceso se habría iniciado incluso en Chile Central, a mediados del 1300 d.C. Asimismo, es necesario aclarar todos los conceptos que se han involucrado en este evento de la prehistoria nacional relacionados con los motivos, intereses, medios, modos y consecuencias de la expansión (p.e., conquista, dominio, influencia, etc.).

En definitiva, hemos planteado nuestras reflexiones a lo largo de todo este trabajo, no con el propósito de exponer nuestras propias preferencias metodológicas e interpretaciones - que de todos modos algo de ellas se halla presente-, sino principalmente para motivar la discusión e investigación en torno a la presencia del Inka en Chile, intentando no olvidar a nadie en esta iniciativa.

\section{AgRADECIMIENTOS}

A Victoria Castro, maestra, colega y amiga, por su constante apoyo e incentivo para desarrollar este tipo de empresas intelectuales, la cual esta vez tuvo su origen en un curso de maestría en arqueología dictado por ella. 


\section{BiBLIOGRAFIA}

Adán, Leonor y Uribe, Mauricio, "Cambios en el uso del espacio en los períodos agroalfareros: un ejemplo de ecozona de quebradas altas, la localidad de Caspana (Provincia El Loa, Il Región)”, en Aclas Segundo Congreso Chileno de Antropología, Colegio de Antropólogos de Chile, t. Il, Providencia, José Benjamin Ramirez Quinteros, Imprenta y Encuademación, 1995, pp. 541-555.

Adán, Leonor y Uribe, Mauricio, "El dominio Inka en las quebradas altas del Loa Superior : un acercamiento al pensamiento político andino". Trabajo presentado al XIV Congreso Nacional de Arqueología Chilena, Museo Regional de Atacama, Copiapó, 1997.

Agüero, Carolina et al., "Una aproximación arqueológica a la etnicidad y el rol de los textiles en la construcción de la identidad cultural en los cementerios de Quillagua (Norte de Chile)". Enviado para su publicación Revista Gaceta Arqueológica Andina, [Lima], 1997.

Aldunate, Carlos, "Estadio agroalfarero en el sur de Chile (500 a ca. 1.800 d.C.)", en Culturas de Chile. Prehistoria, Jorge Hidalgo et. al. (eds.), Santiago, Edit. Andrés Bello, 1989, pp. 329-348.

Aldunate, Carlos, "Arqueologia en el pukara de Turi”, Boletin del Miseo regional de la Araucania, [Temuco], t. II, nro. 4 (1991), pp. 61-78.

Álvarez, Luis, "Metalurgia prehispana Inca en un sector costero marginal del imperio", Revista Diálogo Andino, [Arica], nro. 11-12 (1992-93), pp. 65-75.

Álvarez, Luis, "Ocupación etnoandina del espacio en valles dulces y valles salados del extremo norte de Chile", en Actas Segundo Congreso Chileno de Antropologia, Colegio de Antropólogos de Chile, t. II, Providencia, José Benjamin Ramírez Quinteros, Imprenta y Encuademación, 1995, pp. 556-558.

Ampuero, Gonzalo, "La cultura Diaguita Chilena (1.200 a 1.470 d.C.)", en Culturas de Chile. Prehistoria, Jorge Hidalgo et. al. (eds.), Santiago, Edit. Andrés Bello, 1989, pp. 286-287.

Berenguer, José, "Recientes hallazgos de evidencias Inkaicas en el sector Santa Bárbara, Alto Loa", Boletín Sociedad Chilena de Arqueologia, [Santiago], nro. 18 (1994), pp. 10-18.

Berenguer, José et al, "Secuencia del arte rupestre en el Alto Loa : una hipótesis de trabajo", en Estudios en Arte Rupestre, Primeras Jornadas de Arte y Arqueología, Carlos Aldunate et al. (eds.), Santiago, Museo Chileno de Arte Precolombino, 1985, pp.87-108.

Bittman, Bente et al, 1978, Cultura Atacameña, Santiago, División de Extensión del Ministerio de Educación, 1978.

Cabeza, Ángel, “El santuario Inca en cerro El Plomo", Revista Creces, [Santiago], vol. 5, nro. 8 (1984), pp. 4-10.

Cabeza, Ángel, El santuario de altura Inca cerro El Plomo, Santiago, Universidad de Chile, 1986.

Cabeza, Ángel y Stehberg, Rubén, "El cacicazgo de Malloa", Nueva Historia, Revista de Historia de Chile, [Londres], vol. 3, nro. 10 (1984), pp. 103-156.

Cabeza, Ángel y Tudela, Patricio, "Estudio de la cerámica del santuario Inca cerro Peladeros, Cajón del Maipo, Chile Central”, Revista Clava, [Viña del Mar], nro. 3 (1987), pp. 112-119.

Castillo, Gastón, "Los períodos Intermedio Tardio y Tardío: desde la cultura Copiapó al dominio Inca", en Culturas prehistóricas de Copiapó, Hans Niemeyer et al. (eds.), Copiapó, Impresos Universitarios S.A., 1998, pp. 163-282.

Castro, Victoria, "Nuevos registros de la presencia Inka en la provincia de El Loa, Chile", Revista Gaceta Arqueológica Andina, [Lima], vol. VI, nro. 21 (1992), pp. 139-154.

Castro, Vietoria, y Corncjo, Luis, "Investigaciones en el pukara de Turi : fase inicial", Revista Gaceta Arqueo-' lógica Andina, [Lima], nro. 17 (1990), pp. 57-66.

Castro, Victoria y Varela, Varinia, "Los caminos del "Reinka" en la región del Loa Superior. Desde la etnografía a la arqueología”. Trabajo presentado al XIV Congreso Nacional de Arqueología Chilena, Museo Regional de Alacama, Copiapó, 1997.

Castro, Victoria et al., 1991, "Paniri : un ejemplo de tecnología agrohidráulica", Boletín del Museo Regional de La Arancanía, [Temuco], t. II. nro. 4 (1991), pp. 123-128.

Castro, Victoria et al., "Arquitectura del pukara de Turi", Boletín del Museo Regional de La Araucania, [Temuco], t. II. nro. 4 (1991), pp. 79-106.

Cornejo, Luis, "El Inka en la región del rio Loa: lo local y lo foráneo", Revista Hombre y Desierto, [Antofagasta], t. II, nro. 9 (1995), pp. 203-212.

Cornely, Francisco, "Cenenterio incásico en el valle del Elqui", Publicaciones de la Sociedad Arqueológica de La Serena, [La Serena], nro. 2 (s.a.), pp. 10-12.

Cornely, Francisco, "Influencia Incaica en la cerámica diaguita chilena", Publicaciones de la Sociedad Arqueológica de La Serena, [La Serena], nro. 2 (1947), pp. I0-13.

Chacon, Sergio y Orcllana, Mario, "El tambo Chungara", en Actas del VIII Congreso Nacional de Arqueología, Sociedad Chilena de Arqueologia. Santiago, Ed. Kultrún Ltda., 1982[1979], pp. 247-255. 
Checura, Jorge, "Funebria Incaica en el cerro Esmeralda (lquique, 1 Región)", Revisia Estudios Atacameños, [San Pedro de Atacama], nro. 5 (1977), pp. 12-141.

Dauelsberg, Percy, "Cerámica del Valle de Azapa", Boletín del Museo Regional de Arica, [Arica], nro.3 (1995 [1959-6l]), pp. 47-51.

Dauelsberg, Percy, "Innovaciones en la clasificación de la cerámica de Arica", Bolelín del Museo Regional de Arica, [Arica], nro. 4 (1995[1959-6I]), pp. 85-86.

Dauelsberg, Percy, “Algunos problemas sobre la cerámica de Arica”, Boletín del Museo Regional de Arica, [Arica], nro. 5 (1995[1959-61]), pp. 94-108.

Dauelsberg, Percy, "La cerámica de Arica y su situación cronológica", Revista Chungará, [Arica], nro. l-2 (1972-73), pp. 17-24.

Dillehay, Tom y Gordon, Américo, "La actividad prehispánica de los Incas y su influencia en La Araucania", en La frontera del estado Inca, Tom Dillehay y P. Netherly (eds.), Oxford, BAR Internattional Series, 1988 (1985), pp. 215-234.

Durán, Eliana y Coros, Carlos, "Un hallazgo Inca en el curso superior del rio Aconcagua (V Región, Chile)”, Boletín del Museo Nacional de Historia Natural, [Santiago], nro. 42 (1991), pp. 169-179.

Eaton, George F., La colección de material osteológico de Machu Picchu, Lima, Sociedad de Arqueología Andina, Edit. Rumi Maqui, 1990[1919]. Traducción y edición de Sonia Guillén Oneeglio.

Focacci, Guillermo, "Descripción de un cementerio Incaico en el valle de Azapa", Revista Chungará, [Arica], nro. 7 (1981), pp. 212-216.

Gallardo, Francisco y Vilches, Flora, "Nota acerca de los estilos de arte rupestre en el Pukara de Turi (Norte de Chile)", Boletín de la Sociedad Chilena de Arqueologia, [Santiago], nro. 20 (1995), pp. 26-28.

Gallardo, Francisco et al., "Arquitectura Inka y poder en el pukara de Turi, norte de Chile", Revista Gaceta Arqueológica Andina, [Lima], nro. 24 (1995). pp. 151-171.

González, Carlos, "El criterio monumentalista y su aplicación en la arquitectura Inka de Chile Central", Boletín de la Sociedad Chilena de Arqueología, [Santiago], nro. 23 (1996), pp. 33-37.

González, Carlos, “¿Funebria Incaica o de yanaconas en Chile Central ? La problemática de las adscripcioncs tempo-culturales", Boletín de la Sociedad Chilena de Arqueología, [Santiago], nro. 25 (1998), pp. 31-36.

González, Carlos y Rodríguez, Arturo, "Análisis de las prácticas funerarias Incaicas de Chile Central", Boletin Museo Regional de La Araucania, [Temuco|, t. II, nro. 4 (1991), pp. 223-234.

González, Paola, Diseños cerámicos de la fase Diaguita-Inca : estructura, simbolismo, color y relaciones culturales, Santiago, Departamento de Antropologia. Facultad de Ciencias Sociales. Universidad de Chile, 1995a.

González, Paola, "Diseños cerámicos de la fase Diaguita-Inca: estructura, simbolismo, color y relacioncs culturales", Revista Hombre y Desierto, [Antofagasta], nro. 9 (1995b), pp. 175-184.

Iribarren, Jorge, "La metalurgia en Chile en época precolombina", Publicación del Depto. de Ciencias Sociales, [La Serena], nro. 2 (1964),

Iribarren, Jorge, "Una mina de explotación Incaica: El Salvador-Provincia de Atacama", Boletín de Prehisłoria, [Santiago], nro. especial (1972-73), pp.67-83.

Iribarren, Jorge, "Ocupación Inca en Atacama y Coquimbo", Boletin del Museo Nacional de Historia Natural, [Santiago], nro. 34 (1975], pp. 111-119.

Iribarren, Jorge, "Manifestations of Inca culture in two provinces of Chile", s.a.

Iribarren, Jorge y Bergholz, Hanz, "El camino del Inca en un sector del Norte Chico", Boletín de Prehistoria, [Santiago], nro. especial (1972-73), pp. 229-266.

Latcham, Ricardo, Alfareria indigena chilena, Santiago, Sociedad Impresora y Litográfica Universo, 1928a.

Latcham, Ricardo, La Prehistoria Chilena, Santiago, Sociedad Impresora y Litográfica Universo, 1928b.

Latcham, Ricardo, "Metalurgia atacameña", Boletín del Museo Nacional de Historia Natural, [Santiago], nro. XV (1936), pp..

Le Paige, Gustavo, "Vestigios arqueológicos Incaicos en las cumbres de la zona atacameña". Revis/a Estudios Atacameños, [Antofagasta], nro. 6 (1978), pp. 36-52.

Lynch, Thomas, "Tambo Incaico Catarpe-Este (Informe de Avance)", Revista Estudios Alacameños. [San Pedro de Atacama], nro. 5 (1977), pp. 142-147.

Lynch, Thomas, "Inka roads in the Atacama: effects ol later use by mounted travellers", Revista Diálogo Andino, [Arica], nro. 14-15 (1996-95), pp. 187-203.

Lynch, Thomas y Núñez, Lautaro, "Nuevas evidencias Inkas entre Kollahuasi y Río Frio (I y Il Regiones del Norte de Chile)", Revista Estudios Alacameños, [San Pedro de Atacama], nro. 11 (1994), pp. $145-164$.

Llagostera, Agustín, "Hipótesis sobre la expansión Incaica en la vertiente occidental de los Andes Meridionales", en Homenaje al Dr. Gustavo Le Paige S.J., Antofagasta, Universidad del Norte, 1976, pp. 203-218.

Massone, Mauricio, Los tipos cerámicos del complejo culiural Aconcagua, Santiago, Departamento de Antro- 
pología. Universidad de Chile, 1978.

Medina, Alberto et al., "Expedición al Cerro El Plomo", [Santiago], (1976), pp. 42-83.

Medina, José T., Los aborijenes de Chile, Santiago, Imprenta Gutemberg, 1882.

Moragas, Cora, "Desarrollo de las comunidades prehispánicas del litoral lquique-desembocadura río Loa", Revista Hombre y Desierto, [Antofagasta], t. II, nro. 9 (1995), pp. 65-80.

Mostny, Grete, "Un cementerio incásico en Chile Central", Boletin del Museo Nacional de Historia Natural, [Santiago], nro. 23 (1947), pp. .

Mostny, Grete, "Ciudades atacameñas", Boletin del Museo Nacional de Historia Natural, [Santiago], nro. 24 (1949), pp.

Mostny, Grete, "La momia del Cerro El Plomo", Boletin del Museo Nacional de Historia Natural, [Santiago], t. 27, nro. 1 (1957), pp. 3-118.

Mostny, Grete, Prehistoria de Chile, Santiago, Edit. Universitaria, 1971.

Munizaga, Carlos, Secuencias culturales de la zona de Arica, en Arqueologia Chilena, R. Schaedel (ed.), Santiago, Universidad de Chile, 1957, pp.

Muñoz, Iván, “Asentamientos e interrelaciones culturales: una aproximación al proceso prehispánico tardío en la Sierra de Arica", Tanvantinsuyu, [Buenos Aires-Sidney], vol. 2 (1996), pp. 44-58.

Muñoz, Iván y Chacama, Juan, "El Inca en la Sierra de Arica", Boletín del Museo Regional de La Araucania, [Temuco], t. ], nro. 4 (1991), pp. 269-284.

Muñoz, Iván et al., "La ocupación prehispánica tardía de Zapahuira y su vinculación a la organización y social Inca", Revista Chungará, [Arica], nro. 18 (1987), pp. 67-89.

Murra, John, "El "control vertical" de un máximo de pisos ecológicos en la economia de las sociedades andinas", en Visita a la provincia de León de Huánuco en 1562, Iñigo Ortiz de Zúniga (Red. de John Murra), Huánuco, 1972, pp. 429-476.

Murra, John, La organización económica del estado Inca, México D.F., Edit. Siglo Veintiuno, 1983 [1955].

Niemeyer, Hans, "Tambo Incaico en el valle de Collacagua (Provincia de Tarapacá)”, Revista Universitaria, [Santiago], año XLVII, nro. 25 (1962), pp. 127-141.

Niemeyer, Hans, "Excavación de un cementerio lncaico en la Hacienda Camarones (Provincia de Tarapacá)", Revista Universitaria, [Santiago], nro. 26 (1963), pp. 207-225.

Niemeyer, Hans, "El yacimiento arqueológico de Huana", Boletín de Prehistoria de Chile, [Santiago], 2-3 (1970), pp. 37-115.

Niemeyer, Hans, "Cementerio Diaguita-Incaico del Alto del Carmen (Departamento de Huasco, Provincia de Atacama, Chile)", Boletín de Prehistoria de Chile, [Santiago], año 3, nro. 4 (1971), pp. 69-86.

Niemeyer, Hans, "La ocupación Incaica en la cuenca alta del rio Copiapó (lll Región de Atacama, Chile)", Revista Comechingonia, [Córdoba], ano 4, nro. especial (1985-86), pp. 165-294.

Niemeyer, Hans, "Estrategia del dominio Inca en el valle de Copiapó", Boletín del Museo Regional de La Araucania, [Temuco], t. I, nro. 4 (1991), pp. 333-372.

Niemeyer, Hans y Rivera, Mario, El camino del Inca en el Despoblado de Atacama, Boletín de Prehistoria de Chile, [Santiago], nro. 9 (1983), pp. 91-193.

Niemeyer, Hans y Schiappacasse, Virgilio, "Patrones de asentamiento Incaico en el Norte Grande de Chile", en La frontera del estado Inca, Tom Dillehay y Patricia Netherly (eds.), Oxford, BAR International Series, 1988[1985], pp. 141-179.

Niemeyer, Hans et al., "Viña del Cerro, expresión metalúrgica Inca en el valle de Copiapó", Revista Creces, [Santiago], vol. 4, nro. 4 (1983), pp. 32-35.

Niemeyer, Hans et al., "Viña del Cerro: metalurgia Inka en Copiapó, Chile", Revista Gaceta Arqueológica Andina, [Lima], nro. 9 (1984), pp. 6-7.

Núñez, Lautaro, "Prospección arqueológica en el norte de Chile", Revista Estudios Arqueológicos, [Antofagasta], nro. 1 (1965a), pp. 9-36.

Núñez, Lautaro, “Desarrollo cultural prehispánico del norte de Chile”, Revista Estudios Arqueológicos, [Antofagasta], nro. 1 (1965b), pp.

Núñez, Lautaro, "Secuencia y cambio en los asentamientos humanos de la desembocadura del Río Loa": Boletín de la Universidad de Chile, [Santiago], nro. 112 (1971), pp. .

Núñez, Lautaro, Tráfico de complementariedad de recursos entre las tierras altas y el Pacífico en el área Centro-sur Andina, vol. I, Tokio, Departamento de Antropologia Cultural, Universidad de Tokio, 1984.

Núñez, Lautaro, Cultura y conflicto en los oasis de San Pedro de Atacama, Santiago, Edit. Universitaria, 1992.

Núñez, Lauta ro y Dillehay, Tom, Movilidad giratoria, armonia social y desarrollo en los Andes Meridionales: patrones de tráfico e interacción económica. Ensayo, Antofagasta, Universidad Católica del Norte, 1995.

Núñez, Patricio, "El camino del Inca", Revista Creces, [Santiago], vol. 2, nro. 10 (1981), pp. 49-57.

Núñez, Patricio, "La antigua aldea de San Lorenzo de Tarapacá, Norte de Chile", Revista Chungará, [Arica], 
nro. 13 (1984). pp. 53-66.

Núfiez, Patricio, "Posibilidades agrícolas y población del Incario en el área atacameña. Norte de Chile", Boletín del Museo Regional de La Araucania, [Temuco], t. 1, nro. 4 (1991a), pp. 259-268.

Núñez, Patricio, "Un canal de regadio Incaico : Socaire-Salar de Atacama", Boletín del Museo Regional de La Araucania, [Temuco], t. 1, nro. 4 (1991b), pp. 145-150.

Piazza, Flavio, "Análisis descriptivo de una aldea lncaica en el sector de Pampa Alto Ramirez", Revista Chungará, [Arica], nro. 7 (1981), pp. 172-210.

Planella, María T. y Stehberg, Rubén, "Etnohistoria y arqueología en el estudio de la fortaleza indigena de cerro Grande de la Compañia", Revista Chungara, [Arica], vol. 26, nro. 1 (1994), pp. 65-78.

Planella, María T. et al., "La fortaleza indigena del cerro Grande de La Compañía (valle del Cachapoal) y su relación con el proceso expansivo meridional Incaico", Bolelin del Museo Regional de La Araucania, [Temucol, t. I, nro. 4 (1991), tomo II, pp. 403-422.

Pollard, Gordon, The cultural ecology of ceramic stage settlement in Atacama Desert, Ann Arbor, PH. D. Dissertation, Columbia University, University Microfilms Int., 1982 [1970].

Quevedo, Silvia y Durán, Eliana, "Ofrendas a los dioses en las montañas: santuarios de altura en la cultura Inka", Boletin del Museo Nacional de Historia Natural, [Santiago], nro. 43 (1992), pp. 193-206.

Raffino, Rodolfo, Los Inkas del Kollasuyu. Origen, naturaleza y transfiguraciones de la ocupación Inka en los Andes Meridionales, Buenos Aires, Edit. Ramos Americana, 1981.

Raffino, Rodolfo, "Inka road research and Almagro's route between Argentina and Chile", Tawantinsuyu, [Buenos Aires-Sidney], vol. I (1995), pp. 36-45.

Raffino, Rodolfo y Stehberg, Rubén, "El Tawantinsuyu y sus fronteras", en Actas y trabajos cientificos Xl Congreso Peruano del Hombre y la Cultura Andina "Augusto Cardich", t. 1, Ayacucho, 1997, pp. 338-361

Reinhard, Johan, "Investigación arqueológica de las plataformas ceremoniales en los volcanes de Copiapó y Jotabeche (Región de Atacama)", Revista Contribución Arqueológica, [Copiapó], nro. 3 (1991), pp. 22-56.

Rivera, Mario y Hyslop, John, "Algunas estrategias para el estudio del camino del Inca en la region de Santiago, Chile", Cuadernos de Historia, [Santiago], nro. 4 (1984), pp. 109-128.

Rodriguez, Arturo et al., "Cerro La Cruz : un enclave económico administrativo lncaico, curso medio del Aconcagua (Chile Central)”, Boletin del Museo Regional de La Araucania, [Temuco], t. II, nro. 4 (1991), pp. 201-222

Rowe, John H., An Introduction to the Archaeology of Cuzco, Papers of the Peabody Museum of American Archaeology and Ethnology, [Cambridge, Massachusetts], vol. XXV1I, nro. 2 (1969[1944]), pp. 3-69.

Rydén, Stig, Archaeologycal researches in the highlands of Bolivia, Göteborg. Etnografiska Museum, 1947.

Sanhueza, Julio, Colosos de Iquique, Iquique, Universidad Arturo Prat, 1986.

Santoro, Calógero, "Camino del Inca en la Sierra de Arica", Revista Chungará, [Arica], nro. 10 (1983), pp. 47-56.

Santoro, Calógero y Muñoz, Iván, "Patrón habitacional Incaico en el área de Pampa Ramírez (Arica, Chile)", Revista Chungará, [Arica], nro. 7 (1981), pp. 144-170.

Santoro, Calógero y Ulloa, Liliana (Eds.), Culturas de Arica, Santiago, División de Extensión del Ministerio de Educación, 1985.

Santoro, Calógero et ah, "El estado Inka y los grupos étnicos en el sistema de riego de Socoroma", Revista C/mu1gará, [Arica], nro. 19 (1987), pp. 144-171

Silva, Osvaldo, "Consideraciones acerca del periodo Inca en la cuenca de Santiago (Chile Central)". Boletín del Museo Arqueologico de La Serena, [La Serena], nro. 16 (1977-78), pp. $211-241$

Silva, Osvaldo, "Rentas estatales y rentas reales en el imperio Inca", Cuadernos de Historia, [Santiago], nro. 1 (1981), pp. 31-64.

Silva, Osvaldo, 1983, “Detuvo la batalla del Maule la expansión Inca hacia el sur de Chile ?”. Cuadernos de Historia, [Santiago], nro. 3 (1983), pp. 7-25.

Silva, Osvaldo, "La expansión Incaica en Chile : problemas y reflexiones", en Actas IX Congreso Nacional de Arqueología, Ja Serena, Sociedad Chilena de Arqueología, 1985, pp. 321-340.

Silva, Osvaldo, ¿Dónde estuvo la frontera meridional del estado Inca en Chile?”, Revisia Comechingonia, [Córdoba], año 4, nro. especial (1985-86), pp. 43-53.

Silva, Osvaldo, "Los Promaucaes y la frontera meridional Incaica en Chile", Cuadernos de Historia, [Santiago], nro. 6 (1986), pp. 7-16.

Silva, Osvaldo, "Reflexiones sobre la influencia Incaica en los albores del Reino de Chile", Boletin del Museo Regional de La Araucania, [Temuco], t. I, nro. 4 (1991), pp. 285-292.

Silva, Osvaldo, "Reflexiones acerca del dominio Incaico en Tarapacá(Chile)", Revista Diálogo Andino. [Arica], nro. 11-12 (1992-93), pp. 73-93.

Silva, Osvaldo, "Fundamentos para identificar las estructuras arquitectónicas lncas en la región de Tarapacá 
(Chile)", Revista Diálogo Andino, [Arica], nro. 13 (1994), pp. 60-87.

Spahni, Jcan C., "Tombes inédites du cimetière atacaménien de Chiu-Chiu (Chili)", Bulletin Société Suisse des Americanistes, [Genéve], nro. 26 (1963), pp. 2-9.

Spahni, Jean C., "Le cimetière atacaménien du Pucara de Lasana. Vallèe du Rio Loa (Chili)", Journal de la Société des Américanistes, [Paris], nro. 53 (1964), pp.

Spahni, Jean C., "Recherches archéologiques à l" embouchedurc du Rio Loa (Côte du Pacifique-Chili)", Journal de la Sociére des Américanistes. [Paris], t. LVI, nro. I (1967), pp. 179-239.

Stehberg, Rubén, "I a fortaleza de Chena y su relación con la ocupación incaica de Chile Ccntral", Publicación Ocastonal del Museo nacional de Historia Vatural, [Santiago], nro. 23 (1976a), pp. 3-37.

Stehberg, Rubén, "Notas arqueológicas del cementerio Incaico de Quilicura. Santiago. Chile", Noticiario Mensual del Museo Nacional de Historia Natural, [Santiago], año XX, nro. 234 (1976b), pp. 5-13.

Stehberg, Rubén, "Estrategia del dominio Incaico en el Chile semiárido y la frontera suroccidental". Boletín del Museo Regional de La Araucania. [Temuco], t. 1, nro. 4 (1991a), pp. 317-332.

Stehberg, Rubén, "Estrategia del dominio Incaico en el Kollasuyo", Boletin del Museo Regional de La Araucanía, [Temuco], t. I, nro. 4 (1991b). pp. 24I-244.

Stehberg, Rubẻn, Instalaciones Incaicas en el norte y centro semiárido de Chile. Santiago, Colección de Antropologia, Centro de Investigaciones Diego Barros Arana, Dirección de Bibliotecas, Archivos y Museos, 1995.

Stchberg, Rubén y Cabeza, Ángel, "Sistema vial lncaico en el Chile semiárido", en Actas del XI Congreso Nacional de Arqueologia Chilena, Santiago, t. III, Sociedad Chilena de Arqueologia, Museo Nacional de Historia Natural, Dirección de Bibliotecas, Archivos y Museos, 1991[1988], pp. 31-40.

Stchberg, Rubén y Cabeza, Ángel, "Sistema vial Incaico en el Chile semiárido", Revista Comechingonia, [Córdoba], año 9, nro, especial (1991), 1991, pp. 153-216.

Stehberg, Rubén y Carvajal, Nazareno, "Recientes reconocimientos del camino del Inca en los términos meridionales del imperio : tramo Alicahue Adentro-Alto Choapa", Revista Clava, [Viña del Mar], nro. 3 (1987), pp. 121-129.

Stehberg, Rubén y Morales, Ramón, "Hallazgo Incaico en Santiago", Noticiario Mensual del Museo Nacional de Historia Natural, [Santiago], nro. 314 (1987), pp. 9-12.

Stehberg, Rubén y Rodríguez, Arturo, "Ofrendas mapuche-Incaicas en el cerro Tren-Tren de Doñihue, valle de Cachapoal", Revista Tawantinsuyu, [Buenos Aires-Sidney], vol. 1 (1995), pp. 29-35.

Stehberg, Rubén et al., "El tambo Conchuca y su relación con la ruta de penetración lnka al centro de Chile", Revista Comechingonia, [Córdoba], año 4. nro. especial (1985), pp. 13-41.

Téllez, Eduardo, "De Incas, Picones y Promaucaes. El derrumbe de la "frontera salvaje" en el confĩn austral del Collasuyo", Cuadernos de Historia, [Santiago], nro. 10 (1990), pp. 60-86.

Uhle, Max, "La esiera de influencia del pais de los Incas". [Lima], (1908), pp. 260-281.

U 'ribe, Mauricio, "Cerámicas arqueológicas de Arica: I ctapa de una revaluación tipológica (periodos Medio y comienzos del Intermedio Tardio)", Revista Ilombre y Desierto, [Antofagasta], nro. 9 (1995), pp. 81-96.

Uribe, Mauricio, "Epilogo para la cerámica de Arica", Boletín de la Sociedad Chilena de Arqueología, [Santiago], nro. 22 (1996a), pp. 32-35.

Uribe, Mauricio, Religión y poder en los Andes del Loa: una reflexión desde la alfareria (periodo intermedio (ardio), Santiago, Memoria de Título, Departamento de Antropologia, Facultad de Ciencias Sociales, Universidad de Chile, 1996b.

I ribe, Mauricio, "Cerámicas arqueológicas de Arica: Il ctapa de una revaluación tipológica (periodos Intermedio Tardío y Tardio)". Ponencia presentada al XII'Congreso Nacional de Arqueología Chilena, Copiapó, Museo Rcgional dc Atacama, 1997.

Varela, Varinia, De Toconce pueblo de alfareros. a Turi pueblo de gentiles, Santiago, Memoria de Título, Departamento de Antropologia, Facultad de Ciencias Sociales. Universidad de Chile, 1992.

Zapater, Horacio, "La autoridad del Inca y la dominación española en el Norte de Chile (1536-1549)", en Acras del V'll Congreso de Arqueologia de Chile, Santiago. vol. II, Edit. Kultrún, 1977, pp. 393-408. 